\title{
Spirituality, Social Support, Pride, and Contentment as Differential Predictors of Resilience and Life Satisfaction in Emerging Adulthood
}

\author{
Marylie W. Gerson \\ Department of Psychology, California Lutheran University, Thousand Oaks, CA, USA \\ Email:mgerson@callutheran.edu
}

How to cite this paper: Gerson, M. W. (2018). Spirituality, Social Support, Pride, and Contentment as Differential Predictors of Resilience and Life Satisfaction in Emerging Adulthood. Psychology, 9, 485-517. https://doi.org/10.4236/psych.2018.93030

Received: January 16, 2018

Accepted: March 27, 2018

Published: March 30, 2018

Copyright $\odot 2018$ by author and Scientific Research Publishing Inc. This work is licensed under the Creative Commons Attribution International License (CC BY 4.0).

http://creativecommons.org/licenses/by/4.0/

\section{(c) (i) Open Access}

\begin{abstract}
This study addressed the possible differential impact of various types of spirituality, perceived social support, and positive emotions on resilience and life satisfaction in emerging adulthood. Undergraduates at two universities $(N=$ 428) completed the Connor-Davidson Resilience Scale (CD-RISC-10; Connor \& Davidson, 2003); Satisfaction With Life Scale (SWLS; Diener et al., 1985); Spirituality Scale (Delaney, 2005) to assess intrapersonal, interpersonal, and transpersonal types of spirituality; Multidimensional Scale of Social Support (MSPSS; Zimet et al., 1988) to assess perceived social support; and Dispositional Positive Emotions Scale (DPES; Shiota et al., 2006) to assess various positive emotions. As hypothesized, intrapersonal spirituality, perceived social support, and positive emotions predicted both resilience and life satisfaction, but differed in their relative contributions to each type of well-being. Intrapersonal spirituality and pride predicted resilience, but perceived social support predicted resilience primarily as mediated through positive emotions. Intrapersonal spirituality, perceived social support, and contentment predicted life satisfaction. Resilience and pride predicted life satisfaction only as mediated through contentment. Although transpersonal spirituality and social support may generate resilience in some populations, needs specific to emerging adulthood may favor factors that promote a focus on meaning and purpose in life, independence, and strength.
\end{abstract}

\section{Keywords}

Resilience, Life Satisfaction, Spirituality, Social Support, Positive Emotions

\section{Introduction}

My grandmother was half native American-a source of suffering in the 
1800s - and her immigrant father was abusive. Despite her difficult childhood, she embraced her mother's love of nature and responded to her father's cruelty as lessons about the kind of person not to choose as a partner and about how not to parent. As a young woman, she left her home in the city, became a farmer, and built a new way of life, fueled by perseverance and faith. She told many stories about the importance of spirituality, pride, and looking within for strength. My grandmother was independent and resilient, but, at the end, I am not sure how satisfied she was with her life.

The field of psychology has come to recognize that health and well-being are more than the absence of illness or distress and the potential importance of such factors as spirituality, social support, and positive emotions for building a good life. Each of these factors is multi-dimensional, however, and how they interact may vary depending on the dimensions considered, as well as on the individual's developmental needs. This study assessed whether distinct facets of spirituality, social support, and positive emotions differentially predict resilience and life satisfaction in emerging adulthood.

\subsection{Psychological Well-Being, Resilience, and Life Satisfaction}

Psychological well-being is not synonymous with happiness. It is multi-faceted (Ryff \& Keyes, 1995) and may best be defined as self-realization or "growth and human fulfillment” (Ryff \& Singer, 2008: p. 14). It may include resilience as well as life satisfaction.

Resilience is itself a complex construct, which has been defined in many ways (Reivich, Gillham, Chaplin, \& Seligman, 2013; Smith, Tooley, Christopher, \& Kay, 2010; Windle, 2011). Basically, it refers to doing better than expected in the context of significant adversity or trauma (Luthar, Cicchetti, \& Becker, 2000; Windle, 2011). Life satisfaction may reflect resilience, but is not a necessary outcome. People can be strong, such that they can manage hardships unusually well, but they may not be particularly satisfied with their lives. Conversely, some people seem to be satisfied and at peace; yet, if they were to be hit by adversity they would crumble. Although resilience may be distinct from life satisfaction, resilient individuals may be more likely to adapt effectively to life's challenges, laying the groundwork for a successful, healthy, and happy future (Cohn, Fredrickson, Brown, Mikels, \& Conway, 2009) and satisfied life (Archana, Kumar, \& Singh, 2014).

Life satisfaction is also complex. It is not synonymous with "feeling happy", nor is it derived from meeting the goals deemed to be important by others (Diener, Emmons, Larsen, \& Griffin, 1985). Life satisfaction involves a favorable, personal assessment of one's circumstances. The value placed on such factors as strength, health, financial resources, productive work, or social relationships varies from person to person. Life satisfaction reflects an individual's own judgment about how well he or she is doing in meeting valued standards (Diener et al., 1985). 
Of particular interest for the present study are factors that may promote resilience and life satisfaction in emerging adulthood. Many studies on resilience are based on children and adolescents (Masten, 1999; Masten \& Reed, 2002) or on the elderly as they face major life challenges with aging and loss (Fombuena et al., 2016), and much research on trauma is based on populations seeking treatment (Bonanno, 2004). More research is needed to understand well-being and resilient adaptation in all stages of adulthood.

Many factors have been linked to psychological well-being. Spirituality and social support are particularly interesting for studies of emerging adulthood, because experiences with them are likely to change profoundly as one enters this stage of development. Emerging adulthood follows a period of transformative neurobiological growth (Yurgelun-Todd, 2007), which paves the way for higher cognitive abilities. It also follows a psychosocial stage focused on completing the separation and individuation process and establishing one's identity (Erikson, 1959) - a process that can continue for a number of years. New interest in spiritual questions may grow from deepened cognitive abilities, and reliance on support systems may feel threatening during this stage of budding independence. Spirituality and social support may also reflect different orientations-spirituality a looking within and social support an external focus-which may have implications for building strength and resilience on the one hand and for life satisfaction on the other.

\subsection{Spirituality}

Spirituality involves finding meaning and purpose in relation to what is considered significant or sacred (Büssing et al., 2014; Piedmont, 1999); a personal belief system that helps a person "make sense" out of life (Fombuena et al., 2016; Selby, Seccaraccia, Huth, Kurrpa, \& Fitch, 2016). Spirituality and religiosity are multi-dimensional, overlapping constructs (Koenig, 2012; Saroglou, 2014) and are often interwoven in research.

Many studies have demonstrated the important positive roles that spirituality can play for psychological well-being (Anum \& Dasti, 2016; Foskett, Marriott, \& Wilson, 2004; Porter, Brennan-Ing, Burr, Dugan, \& Karpiak, 2017), life satisfaction (Koenig, 2007), and resilience (Fombuena et al., 2016; Smith \& Carlson, 1997). Spirituality or religion may benefit the individual through many mechanisms (Oman \& Thoresen, 2005). Some findings point to the social support system conferred by shared beliefs or rituals, social networks (Miller \& Kelley, 2005), or feelings of acceptance (Seybold \& Hill, 2001). Other studies report benefits that go beyond social support, such as a sense of existential certainty (Miller \& Kelley, 2005) or attributions of purpose and meaning to negative life events (Seybold \& Hill, 2001). Religiosity and spirituality may also benefit people through an impact on positive emotions (Van Cappellen, Toth-Gauthier, Saroglou, \& Fredrickson, 2016).

Spirituality includes intrapersonal, interpersonal, and transpersonal dimen- 
sions (Delaney, 2005; Fombuena et al., 2016). Intrapersonal spirituality emphasizes a personal search for purpose and meaning, interpersonal spirituality involves connections with others, and transpersonal spirituality focuses on relating to a higher power. Transcendent emotions from religion have been found to promote life satisfaction in middle-aged adults (Van Cappellen et al., 2016), but spiritual transcendence may be associated with distress in university students (Burris, Brechting, Salsman, \& Carlson, 2009). Other research has found the size of one's social support network to correlate positively with interpersonal, negatively with transpersonal, and not at all with intrapersonal spirituality (Fombuena et al., 2016). Further research is needed to determine the role that spirituality may play and how each dimension functions in emerging adulthood.

\subsection{Social Support}

The importance of social relationships for health has long been noted (Cassell, 1976; Cobb, 1976; Hill, Payne, Jackson, Stine-Morrow, \& Roberts, 2014; Smith \& Carlson, 1997), but findings for their benefits vary. Characteristics of the source, recipient, and circumstances of support impact how it is received. Social relationships and comfort during times of distress, such as following the death of a spouse, may be helpful (Infuma \& Luthar, 2017), but support can also add to stress if the recipient is concerned about burdening others (Donnellan, Bennett, \& Soulsby, 2017; Fombuena et al., 2016) or if the support has negative implications regarding self-mastery among the needy, infirmed, elderly (Janssen, Regenmortel, \& Abma, 2011; Varni, Setoguchi, Rappaport, \& Talbot, 1992), or young adult. Social support predicts life satisfaction in some studies (Infuma \& Luthar, 2017; Jiménez Ambriz, Izal, \& Montorio, 2012), but not in others (Perrier, Boucher, Etchegary, Sadava, \& Molnar, 2010), and it does not consistently predict resilience in young adults (Gerson, Fahmy, Glossbrenner, \& Mullen, 2015). The connections between social support and different types of well-being are complex and deserve further investigation (Secor, Limke-McLean, \& Wright, 2017).

\subsection{Positive Emotions}

Both spirituality and social support can be sources of strength or comfort, depending on how they are used and their meanings for the individual. They may increase well-being directly or as they are mediated through the positive emotions they confer. They may also differ in the positive emotions they promote.

According to the broaden-and-build theory (Fredrickson, 2004), positive emotions not only signal well-being, but more importantly, they produce optimal functioning by broadening the mindset. They promote tendencies to explore, create, play, and savor life circumstances, thereby building emotional, social, intellectual, and physical resources in the moment (Fredrickson, 1998, 2001). These resources then provide reserves that can be drawn on in the future for coping with stressful situations (Fredrickson, 1998, 2001). Positive emotions may 
both result from and help build resilience and flourishing (Fredrickson, 2004).

Many emotions have been identified as potentially important (Fredrickson, 2013; Shiota, Keltner, \& John, 2006). Studies often group the positive emotions together (Fredrickson, 2013), but each emotion may have characteristics especially conducive to specific types of well-being. For example, contentment "emerges when people interpret their current circumstances as... satisfying" (Fredrickson, 2013: p. 5), and is associated with savoring one's situation (Fredrickson, 1998). Transcendent emotions, such as awe, gratitude, love, and peace, have been found to promote life satisfaction in middle-aged adults (Van Cappellen et al., 2016). Pride has been found to contribute to perseverance and achievement (Fredrickson, 2013; Williams \& DeSteno, 2008), which may help build resilience.

Pride is often maligned and associated with hubristic arrogance, conceit, and shame, and is rarely associated in a positive way with spirituality or religion (Tracy \& Robins, 2007a). But pride is a complex emotion that also has a healthy form. According to the Authentic/Hubristic Model of Pride (A/H Model; Tracy \& Robins, 2007c), authentic pride adaptively promotes achievement-oriented behaviors and is associated with positive personality traits, self-esteem, accomplishment, and confidence (Tracy, Cheng, Robins, \& Trzesniewski, 2009; Tracy \& Robins, 2007b). It has been linked to attributing events to one's own behaviors, such that happy outcomes are attributed to hard work or effort and unhappy outcomes to specific behaviors that can be improved in the future (Tracy \& Robins, 2007d, 2014). A person may learn from a mistake, try harder next time, or try to right a wrong.

The attributional style associated with authentic pride is consistent with an explanatory style found to promote resilience in young adults. A personal control explanatory style, in which adverse events are attributed to specific, temporary, and changeable (controllable) aspects of oneself, has been found to help undergraduates resist distress (Gerson \& Fernandez, 2013). Rather than engaging either in characterological self-blame or blaming outside factors, a personal control explanatory style considers aspects of the self that may have been responsible for an adverse event or that could be modified to prevent adversity in the future. It involves behavioral self-blame, wherein one considers how a negative event may have resulted from something one did wrong or could do differently in the future, as well as other characteristics that one can change, such as complacency or passivity.

Pride appears to have much in common with a mindset conducive to persisting in the face of adversity. It is a self-conscious emotion (Tracy \& Robins, 2004) that motivates people to persevere despite an absence of outside rewards (Williams \& DeSteno, 2008) and correlates with measures of self-control (Carver, Sinclair, \& Johnson, 2010). Pride in one's personality, efforts to exert control, and sense of mastery are among the factors that have been associated with resilience in older adults (Janssen et al., 2011). 
Positive emotions are strongly associated with well-being as a whole. Certain emotions, such as pride, may be especially conducive to the independence and strength needed for resilience. Others, such as contentment, may foster a sense of serenity and life satisfaction. Furthermore, such factors as spirituality and social support may foster some emotions more than others, thereby differentially impacting the various forms of well-being.

\subsection{The Present Study}

The present study explored the distinctive predictors of resilience and life satisfaction in emerging adulthood, and the roles that spirituality, social support, and particular positive emotions may play in these processes. Most university students are at a stage of development in which they are both newly capable of fully-developed abstract thought and finalizing the separation-individuation process as they begin to establish their lives as independent adults. These factors may set the stage for a personal search for spiritual meaning and pride in managing challenges on one's own; hence, intrapersonal spirituality and pride may be especially important for resilience at this stage. Life satisfaction may especially benefit from the meaning-making inherent in intrapersonal spirituality, friendships and feelings of connection to others, and the comfort derived from spirituality, social support, and resilience. In contrast, relying on others for support may feel threatening to the young adult's emerging independence and, therefore, be less conducive to building resilience.

The following hypotheses were tested with university students:

- Resilience will be significantly and positively predicted by intrapersonal spirituality (Hypothesis 1), overall positive emotions (Hypothesis 2), and the positive emotion of pride (Hypothesis 3). Resilience will not be positively predicted by perceived social support (Hypothesis 4 ).

- Life satisfaction will be significantly and positively predicted by intrapersonal spirituality (Hypothesis 5), overall positive emotions (Hypothesis 6), the positive emotion of contentment (Hypothesis 7), perceived social support (Hypothesis 8), and resilience (Hypothesis 9).

Additional analyses explored relationships among all variables and mediational pathways predicting resilience and life satisfaction.

\section{Method}

\subsection{Procedure}

This study complied with the American Psychological Association's (APA, 2002) ethical guidelines for research with human participants and was approved by the university's Institutional Review Board (IRB). Volunteers were recruited through announcements in undergraduate classes and postings on the universities' psychology study sites. The study was one of many available to students for research participation credit. It was described as involving the completion of several online questionnaires to assess predictors of resilience in university stu- 
dents. Interested students were directed to an online link to the study materials. The link began with an informed consent form detailing the procedure and notifying participants of their rights. It informed participants that the study would require approximately 30 minutes of their time and would involve completing several questionnaires; that their responses would be confidential, no names would be attached to any responses, and all data would be kept in a password-protected file for 3 years; and that their participation was entirely voluntary and they were free to withdraw from the study at any time without prejudice. It also provided participants with the principal investigator's email address and encouraged them to contact her with any questions or concerns before, during, or after the study. Potential incentives included research participation credit, an emailed summary of the findings, advancing an understanding of what factors predict well-being, and an opportunity to participate in research on campus. Students who electronically indicated that they were at least 18 years of age and wished to participate were directed to the questionnaires. Those who chose not to participate were directed out of the system to a page that thanked them for their time.

\subsection{Measures}

Measures included a demographic questionnaire for the purpose of describing the sample; the Connor-Davidson Resilience Scale (CD-RISC-10; Connor \& Davidson, 2003) to assess resilience; Satisfaction With Life Scale (SWLS; Diener et al., 1985) to assess life satisfaction; Spirituality Scale (SS; Delaney, 2005) to assess intrapersonal, interpersonal, and transpersonal types of spirituality; Multidimensional Scale of Social Support (MSPSS; Zimet, Dahlem, Zimet, \& Farley, 1988) to assess perceived social support; and the Dispositional Positive Emotions Scale (DPES; Shiota et al., 2006) to assess various positive emotions, including pride and contentment.

1) Resilience. The CD-RISC-10 is a 10 -item self-report scale developed by Connor and Davidson (2003) to assess resilience. It is designed to reflect a resilient mindset and includes such items as, "I am able to adapt when changes occur". Statements are rated on a 5-point scale ranging from 0 (not true at all) to 4 (true nearly all the time) and are totaled for a final score. The end-points were renumbered in the present study to range from 1 to 5 . The scale has been widely used in research and has been found to have adequate reliability and validity (Connor \& Davidson, 2003). Internal consistency for the measure is reported to range from .78 and .91 and test-retest reliability to range from .78 and .88 (Connor \& Davidson, 2003). Internal consistency (Cronbach's $\alpha$ ) for the present study was .88 .

2) Life satisfaction. The SWLS is a 5 -item scale developed by Diener et al. (1985) to assess satisfaction with life. It includes such items as, "I am satisfied with my life". Statements are rated on a 7-point scale ranging from 1 (strongly disagree) to 7 (strongly agree) and are totaled for a final score. The scale has been widely used in research and has been found to have adequate reliability and 
validity (Diener et al., 1985). Subsequent empirical findings continue to support the validity of the construct and usefulness of the measure (Pavot \& Diener, 2008). Cronbach's $\alpha$ for the present study was .85 .

3) Spirituality. The SS is a 22 -item self-report instrument developed by Delaney (2005) to assess various aspects of spirituality unrelated to a particular religious affiliation. Statements are rated on a 6-point scale ranging from 1 (strongly disagree) to 6 (strongly agree) and can be added to form three subscales as well as a total score. Four statements assess intrapersonal spirituality (Self-Discovery Spirituality) (e.g., "I have a sense of purpose."), six assess interpersonal spirituality (Relationship Spirituality) (e.g., "I value maintaining and nurturing my relationships with others."), and 12 assess transpersonal spirituality (Eco-Awareness Spirituality) (e.g., "I believe in a Higher Power/Universal Intelligence."). Delaney (2005) found Cronbach's as to be .94 for the total SS and to range from .81 to .94 for the subscales, and reported the measure to be valid and reliable for assessing spirituality. Cronbach's as for the present study were .81 for intrapersonal, .78 for interpersonal, .90 for transpersonal, and .91 for overall spirituality.

4) Social support. Zimet et al. (1988) developed the MSPSS to assess the perceived availability of support from others. The MSPSS consists of 12 items rated on a 7-point scale ranging from 1 (very strongly disagree) to 7 (very strongly agree). Items can be totaled for an overall score or to create three subscales (family, friends, and significant other) with four items each. Cronbach's as are reported to range from .85 to .91 for total and subscale scores and test-retest reliability over a 2- to 3-month period to range from .72 to .85 (Zimet, Powell, Farley, Werkman, \& Berkoff, 1990). Cronbach's as for the present study were .90 for the total score and .92 for support from family, .92 for support from friends, and .93 for support from a significant other.

5) Positive emotions. Shiota et al. (2006) developed the DPES to assess seven enduring positive emotions: pride (e.g., "I am proud of myself and my accomplishments."), contentment (e.g., "I am at peace with my life."), joy (e.g., "I am an intensely cheerful person."), amusement (e.g., "I find humor in almost everything."), love (e.g., "I love many people."), compassion (e.g., "It's important to take care of people who are vulnerable."), and awe (e.g., "I feel wonder almost every day."). The DPES consists of 38 items rated on a 7-point scale ranging from 1 (strongly disagree) to 7 (strongly agree). Each subscale consists of either five (pride, contentment, compassion, and amusement) or six items (joy, love, and awe). Cronbach's as are reported to range from .75 to .92 across subscales and intercorrelations support distinct constructs (Shiota et al., 2006). Cronbach's as for the present study were .82 for pride, .91 for contentment, .87 for joy, .85 for amusement, .86 for love, .89 for compassion, .85 for awe, and .94 for the total score.

\subsection{Participants}

Participants were undergraduate volunteers attending either a small, private, re- 
ligiously-affiliated university in southern California or a large, public university in Utah. Twenty-four outliers were removed from the data set (see Data Preparation under Results), resulting in a final sample of 428 participants (238 private university students and 190 public university students). The final sample ranged in age from 18 to 46 years $(M=21.17, S D=3.83)$, included more females $(68 \%)$ than males (31.8\%), and was primarily Caucasian (70.1\%), followed by Hispanic (15.9\%), Asian (4.4\%), African American (2.3\%), Mixed Ethnicity (2.1\%), and Other (4.4\%). Most students were in their first year at the university (36.9\%), followed by second (25.2\%), third (19.2\%), fourth (14.7\%), and fifth years (2.1\%), or "other" (1.9\%). Majors included the social and behavioral sciences (47.4\%), natural sciences or medical preparation (28.5\%), and other areas (23.4\%).

All but 7 students reported that they expected to earn research credit or extra credit for their participation in the study. Other incentives for participating included receiving a summary of the research findings, advancing knowledge in the field, and participating in research on campus.

Although most participants in both university samples were 21 years of age, female, Caucasian, in their first year of study, and majoring in the social and behavioral sciences, demographics of the two university samples differed statistically in a number of ways. The range in ages differed, such that the private university students were significantly younger $(M=20.11, S D=1.84$, Median $=20$, Mode $=21)$ than the public university students $(M=22.50, S D=5.07$, Median $=$ 21$, Mode $=21), t(227.312)=-6.17, p<.001,95 \% C I[-3.16,-1.63]$, Cohen's $d=$ 0.69 , with a medium effect size. The private university students had also completed more years in college $(M=2.47, S D=1.24$, Median $=2$, Mode $=1)$ than the public university students $(M=1.98, S D=1.23$, Median $=2$, Mode $=1)$, $t(406.99)=4.14, p<.001,95 \% C I[0.26,0.73]$, Cohen's $d=0.40$, with a small effect size. The private university sample had a larger proportion of females (76.1\%) to males $(23.5 \%)$ than the public university $(57.9 \%$ females, $42.1 \%$ males), $\chi^{2}(1)=16.59, p<.001$. The private university sample was also somewhat more diverse ethnically (private university sample: 60.9\% Caucasian, $21.4 \%$ Hispanic, 6.3\% Asian, 3.4\% African American, 1.7\% Mixed Ethnicity, and 6.3\% Other, public university sample: $81.6 \%$ Caucasian, $8.9 \%$ Hispanic, $2.1 \%$ Asian, 1.1\% African American, 2.6\% Mixed Ethnicity, and 3.7\% Other), $\chi^{2}(5)=28.07$, $p<.001$. Finally, majors differed in proportions, such that the private university had a larger percentage of social and behavioral science majors (54\%) and smaller percentage of natural science majors $(25 \%)$ than the public university ( $40 \%$ and $34 \%$, respectively), $\chi^{2}(2)=8.00, p=.018$.

\section{Results}

\subsection{Data Analyses}

Power was assessed with $G^{\star}$ Power 3.1 (Faul, Erdfelder, Lang, \& Buchner, 2007). Power with a sample of over 400 was acceptable for a medium effect. 
SPSS 25 was used for most analyses. All statistical tests were two-tailed and adopted an alpha level of .05 for significance. Size of effect was assessed by $R^{2}$ for linear regression analyses, Cohen's (1992) $d$ for $t$-tests, and $\eta_{\text {partial }}^{2}$ for analyses of variance. Interpretations used cut-offs recommended by Cohen (1992) for squared values of $r$ (.01 for small, .09 for medium, and .25 for large), $r$ (.10 for small, .30 for medium, and .50 for large), and $d$ (.20 for small, .50 for medium, and .80 for large). Cut-offs for $\eta_{\text {partial }}^{2}$ were .01 for small, .06 for medium, and .13 for large effects.

Path analyses were conducted using Hayes' (2013) PROCESS computational tool (available free through Andrew Hayes' website at http://www.afhayes.com). PROCESS estimates unstandardized model coefficients, standard error, $t$ - and $p$-values, and confidence intervals using OLS regressions for continuous outcomes. Size of effect is reported as $R^{2}$ for direct paths and as proportions of total effects for indirect paths. Inferential tests for indirect effects were based on bias-corrected bootstrap confidence intervals with 10,000 bootstrap samples. Results from the Sobel normal theory test for mediation effects and standardized coefficients were computed as well.

All hypotheses were tested with linear regressions. Resilience was regressed on intrapersonal spirituality to test Hypothesis 1; on overall positive emotions to test Hypothesis 2; on pride to test Hypothesis 3; and on overall perceived social support to test Hypothesis 4. Life satisfaction was regressed on intrapersonal spirituality to test Hypothesis 5; on overall positive emotions to test Hypothesis 6; on contentment to test Hypothesis 7; on overall perceived social support to test Hypothesis 8; and on resilience to test Hypothesis 9. Path analyses also tested for possible mediation effects through positive emotions for Hypotheses 4 and 9.

\subsection{Data Preparation}

Because regression analyses are sensitive to data points with large residuals or high leverage, data used in regressions were reviewed using Mahalanobis Distance, Cook's Distance, and Centered Leverage Value tests. Highly unusual scorers $(p<.001)$ on at least two of the three tests were excluded from analyses $(n=24)$. Outliers were disproportionately male (13 males and 11 females), $\chi^{2}(1)=$ $5.12, p=.024$, and enrolled at the public university (16 public university students and 8 private university students), $\chi^{2}(1)=4.55, p=.033$, but did not differ significantly on other demographics.

Fewer than $1 \%$ of values were missing for variables involved in hypothesis tests and Little's MCAR test indicated that the pattern of missing values was completely at random $(p>.05)$ in most cases. Missing values were estimated using the Expectation-Maximization procedure.

Visual inspection of scatter plots of the residuals, P-P plots, and Q-Q plots indicated approximate homoscedasticity and normality for variables. The Durbin-Watson test of independence between variables was within an acceptable 
range of -2.5 and +2.5 and values for tolerance (over 0.20 ) and variance inflation factor (under 5.00) for multicollinearity were acceptable for all combinations of variables analyzed.

Table 1 presents means and standard deviations for all scales. Scores were somewhat higher than the midpoint. A MANOVA comparing the two university samples on scales was significant, Pillai's Trace $F(15,412)=7.47, p<.001$, $\eta_{\text {partial }}^{2}=.21$. Relative to participants in the public university sample, private university students scored lower on transpersonal spirituality, overall spirituality, and joy, and higher on social support from friends. Effect sizes were small for joy and social support from friends, medium for overall spirituality, and nearly large for transpersonal spirituality. Subsequent analyses included assessments of whether findings for regression analyses were moderated by university sample, but unless noted otherwise, there were no significant interactions between predictors and university sample.

\section{Findings}

Results are presented separately for predictors of resilience and life satisfaction. Each section begins with findings for intrapersonal spirituality, followed by social support and positive emotions. Resilience is also considered as a predictor of life satisfaction. Possible pathways of influence among predictors are described

Table 1. Descriptive statistics for scales.

\begin{tabular}{|c|c|c|}
\hline Variable & $M$ & $S D$ \\
\hline Resilience & 38.69 & 6.30 \\
\hline Life satisfaction & 25.56 & 6.02 \\
\hline Overall spirituality & 104.78 & 16.18 \\
\hline Intrapersonal spirituality & 20.09 & 3.13 \\
\hline Interpersonal spirituality & 31.38 & 3.65 \\
\hline Transpersonal spirituality & 53.31 & 12.33 \\
\hline Overall social support & 70.27 & 11.22 \\
\hline Social support by family & 23.19 & 5.31 \\
\hline Social support by friends & 23.33 & 4.29 \\
\hline Social support by significant other & 23.75 & 5.01 \\
\hline Overall positive emotions & 199.54 & 29.20 \\
\hline Pride & 26.91 & 4.82 \\
\hline Contentment & 25.23 & 5.72 \\
\hline Amusement & 26.82 & 5.84 \\
\hline Joy & 30.58 & 6.33 \\
\hline Compassion & 29.86 & 4.48 \\
\hline Love & 29.69 & 6.87 \\
\hline Awe & 30.45 & 6.36 \\
\hline
\end{tabular}

Note. $N=428$. 
as well. Table 2 presents all correlations.

1) Predictors of resilience. All measures of spirituality correlated significantly and positively with resilience. As shown in Table 2, correlations were large for intrapersonal spirituality, medium for interpersonal, and small for transpersonal spirituality. When subscales were combined to form a total score (overall spirituality), the correlation with resilience was medium in size. As

Table 2. Zero-order correlations for scales.

\begin{tabular}{|c|c|c|c|c|c|c|c|c|c|c|c|c|c|c|c|c|c|c|}
\hline & & 1 & 2 & 3 & 4 & 5 & 6 & 7 & 8 & 9 & 10 & 11 & 12 & 13 & 14 & 15 & 16 & 17 \\
\hline 1 & Resilience & - & & & & & & & & & & & & & & & & \\
\hline \multirow{2}{*}{2} & Life & .49 & & & & & & & & & & & & & & & & \\
\hline & satisfaction & $* * *$ & - & & & & & & & & & & & & & & & \\
\hline \multirow{2}{*}{3} & Overall & .35 & .33 & & & & & & & & & & & & & & & \\
\hline & spirituality & $* * *$ & $* * *$ & - & & & & & & & & & & & & & & \\
\hline \multirow{2}{*}{4} & Intrapersl. & .55 & .55 & .69 & - & & & & & & & & & & & & & \\
\hline & spirituality & $* * *$ & $* * *$ & $* * *$ & - & & & & & & & & & & & & & \\
\hline \multirow{2}{*}{5} & Interpersl. & .32 & .31 & .64 & .57 & & & & & & & & & & & & & \\
\hline & spirituality & $* * *$ & $* * *$ & $* * *$ & $* * *$ & - & & & & & & & & & & & & \\
\hline \multirow{2}{*}{6} & Transpersl. & .22 & .20 & .95 & .49 & .40 & & & & & & & & & & & & \\
\hline & spirituality & $* * *$ & $* * *$ & $* * *$ & $* * *$ & $* * *$ & - & & & & & & & & & & & \\
\hline \multirow{2}{*}{7} & Overall & .37 & .53 & .34 & .48 & .45 & .19 & - & & & & & & & & & & \\
\hline & support & $* * *$ & $* * *$ & $* * *$ & $* * *$ & $* * *$ & $* * *$ & - & & & & & & & & & & \\
\hline \multirow{2}{*}{8} & Family & .30 & .42 & .30 & .36 & .32 & .21 & .77 & & & & & & & & & & \\
\hline & support & $* * *$ & $* * *$ & $* * *$ & $* * *$ & $* * *$ & $* * *$ & $* * *$ & - & & & & & & & & & \\
\hline \multirow{2}{*}{9} & Friends & .35 & .43 & .22 & .36 & .34 & .10 & .76 & .40 & & & & & & & & & \\
\hline & support & $* * *$ & $* * *$ & $* * *$ & $* * *$ & $* * *$ & $*$ & $* * *$ & $* * *$ & - & & & & & & & & \\
\hline \multirow{2}{*}{10} & Sig. other & .22 & .38 & .25 & .38 & .38 & .12 & .76 & .33 & .43 & & & & & & & & \\
\hline & support & $* * *$ & $* * *$ & $* * *$ & $* * *$ & $* * *$ & $*$ & $* * *$ & $* * *$ & $* * *$ & - & & & & & & & \\
\hline \multirow{2}{*}{11} & Overall & .59 & .60 & .55 & .63 & .52 & .40 & .55 & .41 & .51 & .36 & & & & & & & \\
\hline & emotions & $* * *$ & $* * *$ & $* * *$ & $* * *$ & $* * *$ & $* * *$ & $* * *$ & $* * *$ & $* * *$ & $* * *$ & - & & & & & & \\
\hline \multirow{2}{*}{12} & Pride & .60 & .57 & .42 & .62 & .37 & .28 & .45 & .35 & .37 & .33 & .73 & - & & & & & \\
\hline & & $* * *$ & $* * *$ & $* * *$ & $* * *$ & $* * *$ & $* * *$ & $* * *$ & $* * *$ & $* * *$ & $* * *$ & $* * *$ & - & & & & & \\
\hline \multirow{2}{*}{13} & Contentmt & .58 & .72 & .44 & .62 & .36 & .31 & .50 & .41 & .42 & .33 & .78 & .73 & & & & & \\
\hline & Contentms. & $* * *$ & $* * *$ & $* * *$ & $* * *$ & $* * *$ & $* * *$ & $* * *$ & $* * *$ & $* * *$ & $* * *$ & $* * *$ & $* * *$ & - & & & & \\
\hline \multirow{2}{*}{14} & Amusemt & .37 & .19 & .20 & .21 & .22 & .14 & .21 & .15 & .27 & 09 & .61 & .27 & .28 & & & & \\
\hline & & $* * *$ & $* * *$ & $* * *$ & $* * *$ & $* * *$ & $* *$ & $* * *$ & $* *$ & $* * *$ & (09 & $* * *$ & $* * *$ & $* * *$ & - & & & \\
\hline \multirow{2}{*}{15} & Joy & .52 & .57 & .51 & .59 & .44 & .39 & .50 & .38 & .42 & .36 & .86 & .61 & .71 & .44 & - & & \\
\hline & joy & $* * *$ & $* * *$ & $* * *$ & $* * *$ & $* * *$ & $* * *$ & $* * *$ & $* * *$ & $* * *$ & $* * *$ & $* * *$ & $* * *$ & $* * *$ & $* * *$ & - & & \\
\hline \multirow{2}{*}{16} & Comnassn & .16 & .20 & .42 & .32 & .47 & .33 & .29 & .18 & .28 & .22 & .56 & .26 & .23 & .30 & .38 & & \\
\hline & Compassin. & $* *$ & $* * *$ & $* * *$ & $* * *$ & $* * *$ & $* * *$ & $* * *$ & $* * *$ & $* * *$ & $* * *$ & $* * *$ & $* * *$ & $* * *$ & $* * *$ & $* * *$ & - & \\
\hline \multirow{2}{*}{17} & Joye & .34 & .42 & .37 & .38 & .41 & .26 & .50 & .42 & .48 & .27 & .76 & .48 & .50 & .33 & .59 & .42 & \\
\hline & Love & $* * *$ & $* * *$ & $* * *$ & $* * *$ & $* * *$ & $* * *$ & $* * *$ & $* * *$ & $* * *$ & $* * *$ & $* * *$ & $* * *$ & $* * *$ & $* * *$ & $* * *$ & $* * *$ & \\
\hline \multirow{2}{*}{18} & Awe & .39 & .34 & .42 & .45 & .35 & .33 & .29 & .17 & .29 & .21 & .71 & .38 & .46 & .41 & .53 & .34 & .40 \\
\hline & AWE & $* * *$ & $* * *$ & $* * *$ & $* * *$ & $* * *$ & $* * *$ & $* * *$ & $* *$ & $* * *$ & $* * *$ & $* * *$ & $* * *$ & $* * *$ & $* * *$ & $* * *$ & $* * *$ & $* * *$ \\
\hline
\end{tabular}

Note. $N=428$. Measures of support are self-ratings of perceived social support. ${ }^{*} p<.05 .{ }^{* *} p<.01 .{ }^{* * *} p<.001$. 
shown in Table 3, when resilience was regressed on overall spirituality, spirituality significantly accounted for a medium portion of the criterion's variance. When resilience was regressed on overall spirituality as well as the three subscales, intrapersonal spirituality was the only significant predictor, uniquely accounting for a medium portion of the criterion's variance, and when resilience was regressed on intrapersonal spirituality alone, the predictor accounted for a large portion of the criterion's variance. Hypothesis 1 was supported.

All measures of social support significantly and positively correlated with resilience (see Table 2). Correlations were small for support from a significant other and medium for support from family or friends. When the subscales were combined to form a total score for social support (overall social support), the correlation with resilience was medium in size. When resilience was regressed on overall social support, social support significantly accounted for a medium portion of the criterion's variance. When the criterion was regressed on overall social support as well as the three subscales, only overall social support was a significant predictor, again uniquely accounting for a medium portion of the variance (see Table 3).

The relative contributions of intrapersonal spirituality and overall social support were tested next. As shown in Table 3, when resilience was regressed on the two variables together, both were significant predictors, but only intrapersonal spirituality uniquely accounted for more than a small portion of the variance.

All positive emotions significantly and positively correlated with resilience (see Table 2). Correlations were large for pride, contentment, and joy; medium for amusement, love, and awe; and small for compassion. When all positive emotions were totaled (overall positive emotions), the correlation with resilience was large. As predicted, both overall positive emotions (Hypothesis 2) and pride (Hypothesis 3) were significant and strong predictors of resilience (see Table 3). When resilience was regressed on the seven emotions as a group, pride was the strongest predictor, followed by contentment and amusement. Joy, compassion, love, and awe were not significant predictors of resilience.

All positive emotions significantly and positively correlated with intrapersonal spirituality as well (see Table 2). Correlations were large for pride, contentment, and joy; medium for compassion, love, and awe; and small for amusement. As shown in Table 4, when intrapersonal spirituality was regressed on the seven emotions together, they predicted a large portion of the variance and all but love were significant predictors. Pride was the strongest predictor, followed by joy, contentment, awe, and compassion. Amusement added negatively to the equation. When intrapersonal spirituality was regressed on pride alone, the predictor accounted for a large portion of the criterion's variance. When pride was regressed on overall spirituality, spirituality accounted for a medium portion of pride's variance. When pride was regressed on overall spirituality as well as the subscales, only intrapersonal spirituality was a significant predictor, uniquely accounting for a nearly large portion of the criterion's variance. A possible mediation effect was tested for intrapersonal spirituality through overall positive 
Table 3. Results from linear regressions for predictors of resilience.

\begin{tabular}{|c|c|c|c|c|c|c|}
\hline Predictor & $\beta^{a}$ & $B$ & $95 \% C I$ & $t$ & $p$ & Semi-partial $r^{2}$ \\
\hline \multicolumn{7}{|c|}{ Spirituality } \\
\hline Overall & .35 & .14 & $.10, .17$ & 7.67 & $<.001$ & .12 \\
\hline Intercept & & 24.49 & & & & \\
\hline \multicolumn{7}{|c|}{$R_{\text {adjusted }}^{2}=.12, F(1,426)=58.85, p<.001 ;$ Durbin-Watson $=1.89$} \\
\hline Overall & -.09 & -.03 & $-.08, .01$ & -1.41 & .159 & .003 \\
\hline Intrapersonal & .58 & 1.17 & $.95,1.40$ & 10.17 & $<.001$ & .17 \\
\hline Interpersonal & .05 & .08 & $-.10, .27$ & .89 & .373 & .001 \\
\hline Transpersonal & - & - & - & - & - & - \\
\hline Intercept & & 16.29 & & & & \\
\hline \multicolumn{7}{|c|}{$R_{\text {adjusted }}^{2}=.30, F(3,424)=62.72, p<.001 ;$ Durbin-Watson $=1.79$} \\
\hline Intrapersonal & .55 & 1.11 & $.95,1.27$ & 13.64 & $<.001$ & .30 \\
\hline Intercept & & 16.43 & & & & \\
\hline \multicolumn{7}{|c|}{$R_{\text {adjusted }}^{2}=.30, F(1,426)=186.03, p<.001 ;$ Durbin-Watson $=1.80$} \\
\hline \multicolumn{7}{|c|}{ Social support } \\
\hline Overall & .37 & .21 & $.16, .26$ & 8.30 & $<.001$ & .14 \\
\hline Intercept & & 23.97 & & & & \\
\hline \multicolumn{7}{|c|}{$R_{\text {adjusted }}^{2}=.14, F(1,426)=68.92, p<.001 ;$ Durbin-Watson $=1.83$} \\
\hline Overall & .37 & .21 & $.09, .33$ & 3.55 & $<.001$ & .16 \\
\hline From family & - & - & - & - & - & - \\
\hline From friends & .11 & .17 & $-.05, .38$ & 1.51 & .132 & .004 \\
\hline From significant other & -.11 & -.14 & $-.33, .04$ & -1.50 & .135 & .004 \\
\hline Intercept & & 23.48 & & & & \\
\hline \multicolumn{7}{|c|}{$R_{\text {adjusted }}^{2}=.15, F(3,424)=25.68, p<.001 ;$ Durbin-Watson $=1.79$} \\
\hline \multicolumn{7}{|c|}{ Intrapersonal spirituality and overall social support } \\
\hline Spirituality & .48 & .97 & $.79,1.15$ & 10.60 & $<.001$ & .18 \\
\hline Social support & .14 & .08 & $.03, .13$ & 3.09 & .002 & .02 \\
\hline Intercept & & 13.60 & & & & \\
\hline \multicolumn{7}{|c|}{$R_{\text {adjusted }}^{2}=.32, F(2,425)=99.66, p<.001 ;$ Durbin-Watson $=1.80$} \\
\hline \multicolumn{7}{|c|}{ Positive emotions } \\
\hline Overall & .59 & .13 & $.11, .14$ & 15.12 & $<.001$ & .35 \\
\hline Intercept & & 13.25 & & & & \\
\hline \multicolumn{7}{|c|}{$R_{\text {adjusted }}^{2}=.35, F(1,426)=228.70, p<.001 ;$ Durbin-Watson $=1.90$} \\
\hline Pride & .60 & .79 & $.69, .89$ & 15.56 & $<.001$ & .36 \\
\hline
\end{tabular}




\section{Continued}

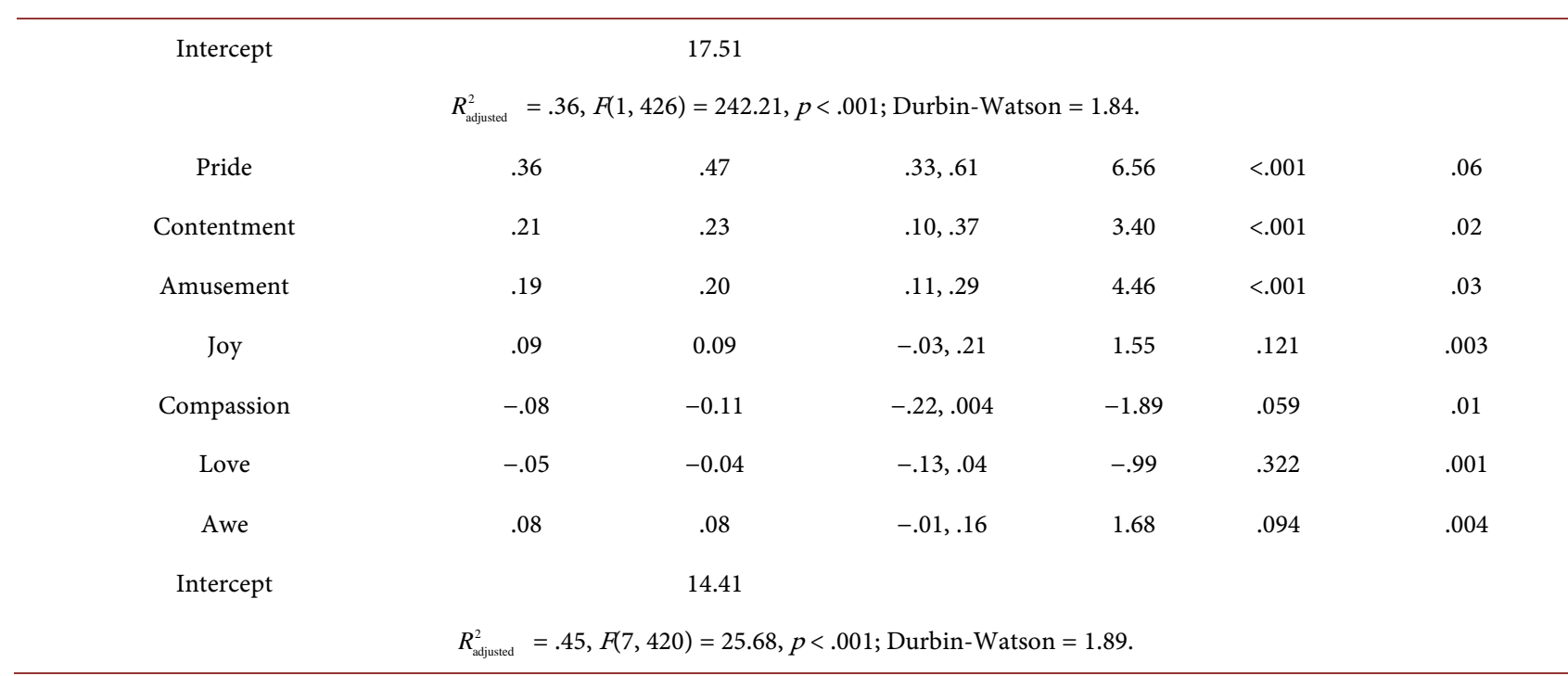

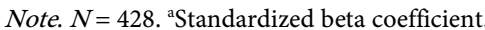

emotions. Because pride was hypothesized to predict resilience and was found to predict both resilience and intrapersonal spirituality, it was tested as a mediator as well. As shown in Table 5, a path analysis indicated a partial mediation effect through positive emotions. Intrapersonal spirituality predicted resilience directly, as well as indirectly through its effect on either overall positive emotions or pride alone. The indirect effect accounted for nearly half of the total effect in both cases.

Correlations with overall social support were significant and positive for all positive emotions (see Table 2). Correlations were large for contentment, joy, and love; medium or nearly medium for pride, compassion, and awe; and small for amusement. As shown in Table 4, when overall social support was regressed on the seven emotions, they accounted for a large portion of the criterion's variance. Only contentment, joy, and love were significant predictors, with love being the strongest. A possible mediation effect was tested for overall social support through overall positive emotions. As shown in Table 5, a path analysis indicated full mediation for overall social support, such that social support only predicted resilience indirectly through its effect on overall positive emotions. Social support was a significant and positive predictor of resilience, but only as mediated through positive emotions. Hypothesis 4 was partially supported.

A moderation effect was found for university sample. As shown in Table 5, the path from overall positive emotions to resilience (Path $b_{1}$ ) was stronger than the path from social support to overall positive emotions (Path $a_{1}$ ) for the private university sample but weaker for the public university sample. The overall pattern of relationships among the variables was the same for both samples, however, with a significant mediation effect through overall positive emotions and no significant direct effect for social support.

2) Predictors of life satisfaction. All measures of spirituality correlated 
Table 4. Results from multiple linear regressions exploring relationships between spirituality and overall social support with positive emotions.

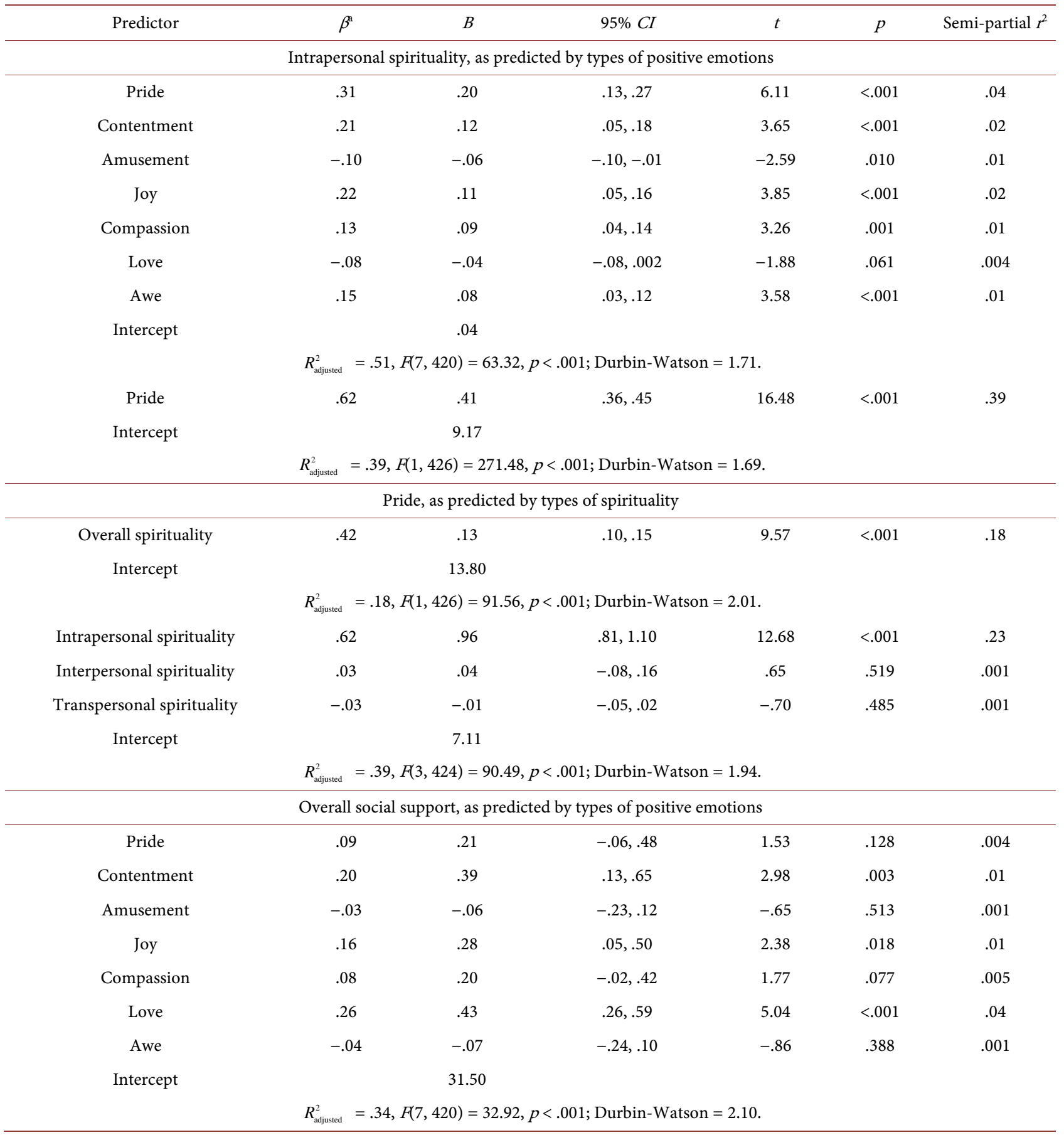

Note. $N=428 .{ }^{\text {a }}$ tandardized beta coefficient.

significantly and positively with life satisfaction (see Table 2). Correlations were medium for overall spirituality, large for intrapersonal, medium for interpersonal, and small for transpersonal spirituality. As shown in Table 6, when life satisfaction was regressed on overall spirituality, spirituality accounted for a medium portion of the criterion's variance. When life satisfaction was regressed on 
Table 5. Results from path analyses for predictors of resilience.

\begin{tabular}{|c|c|c|c|c|}
\hline Variable & $\begin{array}{c}\text { Beta } \\
\text { coefficient }\end{array}$ & 95\% CI for coefficient & $t$ & $p$ \\
\hline \multicolumn{5}{|c|}{ Resilience, as predicted by intrapersonal spirituality, with overall positive emotions as a mediator } \\
\hline Total effect for spirituality & $1.11(.55)$ & $.95,1.27$ & 13.52 & $<.001$ \\
\hline Direct effect for spirituality & $.59(.28)$ & $.39, .80$ & 5.79 & $<.001$ \\
\hline Indirect effect through emotions & $.51(.27)$ & $.39, .66$ & & \\
\hline $\begin{array}{c}\text { Path } a_{1} \\
\text { (spirituality } \rightarrow \text { emotions) }\end{array}$ & $5.91(.65)$ & $5.23,6.58$ & 17.24 & $<.001$ \\
\hline $\begin{array}{c}\text { Path } b_{1} \\
\text { (emotions } \rightarrow \text { resilience) }\end{array}$ & $.09(.42)$ & $.07, .11$ & 8.14 & $<.001$ \\
\hline $\begin{array}{c}\text { Path } c^{2} \\
\text { (spirituality } \rightarrow \text { resilience) }\end{array}$ & $.59(.28)$ & $.39, .80$ & 5.79 & $<.001$ \\
\hline \multicolumn{5}{|c|}{$R^{2}=.30$ for total effect. Sobel $z=7.35, p<.001$ for indirect effect. Ratio of indirect to total effect $=.46$} \\
\hline \multicolumn{5}{|c|}{ Resilience, as predicted by intrapersonal spirituality, with pride as a mediator } \\
\hline Total effect for spirituality & $1.11(.55)$ & $.95,1.27$ & 13.52 & $<.001$ \\
\hline Direct effect for spirituality & $.58(.29)$ & $.38, .78$ & 5.69 & $<.001$ \\
\hline Indirect effect through pride & $.53(.26)$ & $.40, .68$ & & \\
\hline $\begin{array}{c}\text { Path } a_{1} \\
\text { (spirituality } \rightarrow \text { pride) }\end{array}$ & $.96(.62)$ & $.84,1.08$ & 15.33 & $<.001$ \\
\hline $\begin{array}{c}\text { Path } b_{1} \\
\text { (pride } \rightarrow \text { resilience) }\end{array}$ & $\begin{array}{l}.55 \\
(.42)\end{array}$ & $.42, .68$ & 8.24 & $<.001$ \\
\hline $\begin{array}{c}\text { Path } \vec{c} \\
\text { (spirituality } \rightarrow \text { resilience) }\end{array}$ & $.58(.29)$ & $.38, .78$ & 5.69 & $<.001$ \\
\hline \multicolumn{5}{|c|}{$R^{2}=.30$ for total effect. Sobel $z=7.25, p<.001$ for indirect effect. Ratio of indirect to total effect $=.48$} \\
\hline \multicolumn{5}{|c|}{ Resilience, as predicted by overall social support, with overall positive emotions as a mediator } \\
\hline Total effect for social support & $.21(.37)$ & $.16, .25$ & 9.19 & $<.001$ \\
\hline Direct effect for social support & $.04(.03)$ & $-.01, .09$ & 1.49 & .137 \\
\hline Indirect effect through emotions & $.17(.34)$ & $.13, .21$ & & \\
\hline $\begin{array}{c}\text { Path } a_{1} \\
\text { (social support } \rightarrow \text { emotions) }\end{array}$ & $1.43(.59)$ & $1.22,1.63$ & 13.67 & $<.001$ \\
\hline $\begin{array}{c}\text { Path } b_{1} \\
\text { (emotions } \rightarrow \text { resilience) }\end{array}$ & $.12(.58)$ & $.10, .14$ & 11.13 & $<.001$ \\
\hline Path $c^{\prime}$ (social support $\rightarrow$ resilience) & $.04(.03)$ & $-.01, .09$ & 1.49 & .137 \\
\hline \multicolumn{5}{|c|}{$R^{2}=.14$ for total effect. Sobel $z=8.62, p<.001$ for indirect effect. Ratio of indirect to total effect $=.81$} \\
\hline \multicolumn{5}{|c|}{ Resilience, as predicted by overall social support, with overall positive emotions as a mediator, for the private university sample ( $n=238$} \\
\hline Total effect for social support & $.24(.43)$ & $.18, .31$ & 7.12 & $<.001$ \\
\hline Direct effect for social support & $.05(.05)$ & $-.03, .12$ & 1.27 & .207 \\
\hline Indirect effect through positive emotions & $.20(.39)$ & $.14, .26$ & & \\
\hline Path $a_{1}$ (social support $\rightarrow$ emotions) & $1.39(.57)$ & $1.09,1.69$ & 9.18 & $<.001$ \\
\hline
\end{tabular}




\section{Continued}

\begin{tabular}{|c|c|c|c|c|}
\hline $\begin{array}{c}\text { Path } b_{1} \\
\text { (emotions } \rightarrow \text { resilience) }\end{array}$ & $.14(.68)$ & $.11, .17$ & 10.04 & $<.001$ \\
\hline $\begin{array}{c}\text { Path } c^{\prime} \\
\text { (social support } \rightarrow \text { resilience) }\end{array}$ & $.05(.05)$ & $-.03, .12$ & 1.27 & .207 \\
\hline \multicolumn{5}{|c|}{$R^{2}=.15$ for total effect. Sobel $z=6.76, p<.001$ for indirect effect. Ratio of indirect to total effect $=.81$. } \\
\hline \multicolumn{5}{|c|}{ Resilience, as predicted by overall perceived social support, with overall positive emotions as a mediator, for the public university sample ( $n=190$} \\
\hline Total effect for social support & $.18(.33)$ & $.12, .24$ & 5.93 & $<.001$ \\
\hline Direct effect for social support & $.04(.05)$ & $-.03, .12$ & 1.13 & .259 \\
\hline Indirect effect through emotions & $.14(.28)$ & $.09, .20$ & & \\
\hline $\begin{array}{c}\text { Path } a_{1} \\
\text { (social support } \rightarrow \text { emotions) }\end{array}$ & $1.50(.62)$ & $1.21,1.80$ & 10.13 & $<.001$ \\
\hline $\begin{array}{c}\text { Path } b_{1} \\
\text { (emotions } \rightarrow \text { resilience) }\end{array}$ & $.09(.45)$ & $.06, .12$ & 5.68 & $<.001$ \\
\hline $\begin{array}{c}\text { Path } c^{c} \\
\text { (social support } \rightarrow \text { resilience) }\end{array}$ & $.04(.05)$ & $-.03, .12$ & 1.13 & .259 \\
\hline
\end{tabular}

Note. PROCESS establishes significance by confidence intervals that do not contain a zero. Where available, $t$ - and $p$-values have been included as well. Results from the Sobel normal theory test for mediation are also provided for simple mediation analyses. Standardized coefficients are provided in parentheses. $N=428$.

overall spirituality as well as the three subscales, intrapersonal spirituality was a significant predictor, followed only by transpersonal spirituality, which added negatively to the equation. Finally, when life satisfaction was regressed on intrapersonal spirituality alone, the predictor accounted for a large portion of the criterion's variance. Hypothesis 5 was supported.

All measures of social support significantly and positively correlated with life satisfaction (see Table 2). Correlations were large for overall social support and medium for all subscales. As predicted (Hypothesis 8), when life satisfaction was regressed on overall social support, social support was a significant, positive, and strong predictor of the criterion (see Table 6). A multiple linear regression with overall social support and the three subscales excluded the total score as redundant (see Table 6), but because overall social support was at least as strong a predictor as the three subscales combined, it was used for subsequent analyses.

The relative contributions of intrapersonal spirituality and overall social support were tested. As shown in Table 6, both variables uniquely accounted for medium portions of life satisfaction's variance.

All positive emotions significantly and positively correlated with life satisfaction (see Table 2). Correlations were large for contentment, pride, and joy; medium for love and awe; and small for compassion and amusement. As shown in Table 6, both overall positive emotions and contentment were significant, positive, and strong predictors of life satisfaction. Hypotheses 6 and 7 were supported. When life satisfaction was regressed on the seven emotions as a group, only contentment was a significant predictor, uniquely accounting for a medium 
Table 6. Results from linear regressions for predictors of life satisfaction.

\begin{tabular}{|c|c|c|c|c|c|c|}
\hline Predictor & $\beta^{a}$ & $B$ & $95 \% C I$ & $t$ & $p$ & Semi-partial $r^{2}$ \\
\hline \multicolumn{7}{|c|}{ Spirituality } \\
\hline Overall & .33 & .12 & $.09, .16$ & 7.16 & $<.001$ & .11 \\
\hline Intercept & & 12.79 & & & & \\
\hline \multicolumn{7}{|c|}{$R_{\text {adjusted }}^{2}=.11, F(1,426)=51.23, p<.001 ;$ Durbin-Watson $=1.95$} \\
\hline Overall & - & - & - & - & - & - \\
\hline Intrapersonal & .59 & 1.13 & $.94,1.33$ & 11.33 & $<.001$ & .21 \\
\hline Interpersonal & .01 & .02 & $-.14, .18$ & .29 & .776 & $<.001$ \\
\hline Transpersonal & -.10 & -.05 & $-.09,-.001$ & -2.03 & .043 & .01 \\
\hline Intercept & & 4.52 & & & & \\
\hline \multicolumn{7}{|c|}{$R_{\text {adjusted }}^{2}=.31, F(3,424)=63.91, p<.001 ;$ Durbin-Watson $=2.00$} \\
\hline Intrapersonal & .55 & 1.06 & $.91,1.21$ & 13.66 & $<.001$ & .30 \\
\hline Intercept & & 4.25 & & & & \\
\hline \multicolumn{7}{|c|}{$R_{\text {adjusted }}^{2}=.30, F(1,426)=186.68, p<.001 ;$ Durbin-Watson $=1.98$} \\
\hline \multicolumn{7}{|c|}{ Social support } \\
\hline Overall & .53 & .29 & $.24, .33$ & 13.05 & $<.001$ & .28 \\
\hline Intercept & & 5.46 & & & & \\
\hline \multicolumn{7}{|c|}{$R_{\text {adjusted }}^{2}=.28, F(1,426)=169.01, p<.001 ;$ Durbin-Watson $=2.04$} \\
\hline Overall & - & - & - & - & - & - \\
\hline From family & .25 & .29 & $.19, .39$ & 5.55 & $<.001$ & .05 \\
\hline From friends & .24 & .34 & $.21, .47$ & 5.08 & $<.001$ & .04 \\
\hline From significant other & .20 & .24 & $.13, .35$ & 4.30 & $<.001$ & .03 \\
\hline Intercept & & 23.48 & & & & \\
\hline \multicolumn{7}{|c|}{$R_{\text {adjusted }}^{2}=.28, F(3,424)=56.56, p<.001 ;$ Durbin-Watson $=2.03$} \\
\hline \multicolumn{7}{|c|}{ Intrapersonal spirituality and overall social support } \\
\hline Spirituality & .39 & .74 & $.58, .14$ & 8.97 & $<.001$ & .11 \\
\hline Social support & .35 & .19 & $.14, .23$ & 8.12 & $<.001$ & .09 \\
\hline Intercept & & -2.43 & & & & \\
\hline \multicolumn{7}{|c|}{$R_{\text {adjusted }}^{2}=.40, F(2,425)=140.51, p<.001 ;$ Durbin-Watson $=2.02$} \\
\hline \multicolumn{7}{|c|}{ Resilience } \\
\hline Resilience & .49 & .46 & $.38, .54$ & 11.46 & $<.001$ & .23 \\
\hline Intercept & & 7.61 & & & & \\
\hline \multicolumn{7}{|c|}{$R_{\text {adjusted }}^{2}=.23, F(1,426)=131.21, p<.001 ;$ Durbin-Watson $=2.03$} \\
\hline \multicolumn{7}{|c|}{ Positive emotions } \\
\hline Overall & .60 & .12 & $.11, .14$ & 15.51 & $<.001$ & .36 \\
\hline Intercept & & .84 & & & & \\
\hline \multicolumn{7}{|c|}{$R_{\text {adjusted }}^{2}=.36, F(1,426)=240.53, p<.001 ;$ Durbin-Watson $=2.01$} \\
\hline
\end{tabular}




\section{Continued}

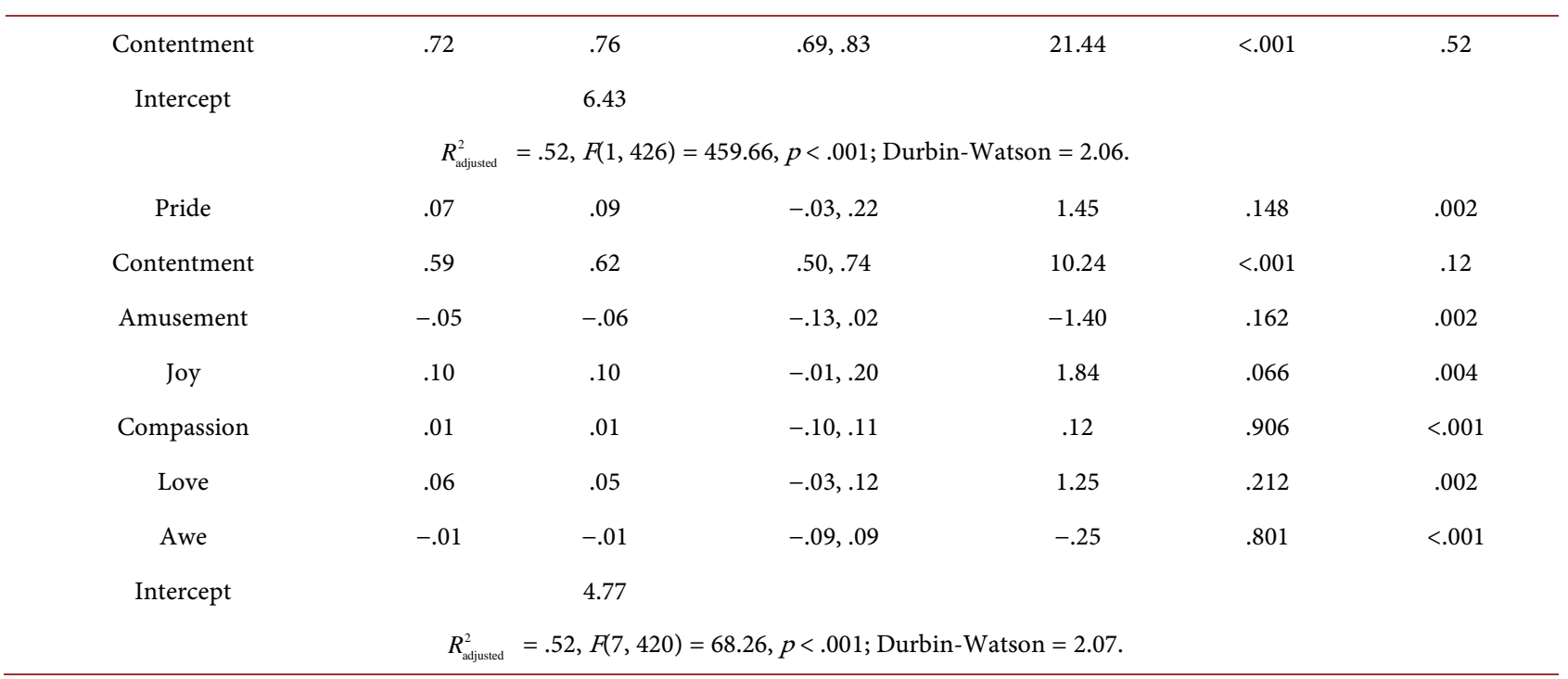

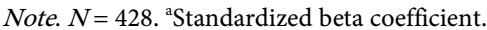

portion of the criterion's variance (see Table 6).

Possible mediation effects were tested through overall positive emotions for both intrapersonal spirituality and overall social support. Because contentment was hypothesized to predict life satisfaction, and was found to predict life satisfaction, intrapersonal spirituality, and overall social support, it was tested as a mediator as well. As shown in Table 7, the effect for intrapersonal spirituality on life satisfaction was partially mediated through positive emotions, with the indirect effect accounting for approximately half of the total effect when mediated through overall positive emotions and for over two thirds of the total effect when mediated through contentment. The effect for overall social support was also partially mediated through positive emotions, with the indirect effect through either overall positive emotions or contentment accounting for approximately half of the total effect.

Finally, the correlation between resilience and life satisfaction was significant, positive, and nearly large (see Table 2). Resilience predicted a significant portion of the criterion's variance, with a nearly large effect (see Table 6). As shown in Table 7, path analyses indicated that the effect of resilience on life satisfaction was partially mediated through positive emotions. The indirect effect accounted for over half of the total effect when mediated through overall positive emotions and for over three quarters of the total effect when mediated through contentment. Hypothesis 9 was partially supported.

Intrapersonal spirituality was linked to resilience through pride, and resilience was linked to life satisfaction through contentment. A path analysis tested a model in which life satisfaction was predicted by intrapersonal spirituality, as partially mediated through pride, resilience, and contentment. As shown in Table 7, the path analysis indicated that intrapersonal spirituality both directly and indirectly predicted life satisfaction, as well as all of the other variables. The 
Table 7. Results from path analyses for predictors of life satisfaction.

\begin{tabular}{|c|c|c|c|c|}
\hline Variable & Beta coefficient & 95\% $C I$ for coefficient & $t$ & $p$ \\
\hline \multicolumn{5}{|c|}{ Life satisfaction, as predicted by intrapersonal spirituality, with overall positive emotions as a mediator } \\
\hline Total effect for spirituality & $1.10(.55)$ & $.91,1.21$ & 14.03 & $<.001$ \\
\hline Direct effect for spirituality & $.55(.20)$ & $.36, .74$ & 5.65 & $<.001$ \\
\hline Indirect effect through emotions & $.51(.36)$ & $.38, .65$ & & \\
\hline $\begin{array}{c}\text { Path } a_{1} \\
\text { (spirituality } \rightarrow \text { emotions) }\end{array}$ & $5.91(.65)$ & $5.23,6.58$ & 17.24 & $<.001$ \\
\hline $\begin{array}{c}\text { Path } b_{1} \\
\text { (emotions } \rightarrow \text { life satisfaction) }\end{array}$ & $.09(.55)$ & $.07, .11$ & 8.24 & $<.001$ \\
\hline $\begin{array}{c}\text { Path } \dot{c} \\
\text { (spirituality } \rightarrow \text { life satisfaction) }\end{array}$ & $.55(.20)$ & $.36, .74$ & 5.65 & $<.001$ \\
\hline \multicolumn{5}{|c|}{$R^{2}=.30$ for total effect. Sobel $z=7.42, p<.001$ for indirect effect. Ratio of indirect to total effect $=.48$} \\
\hline \multicolumn{5}{|c|}{ Life satisfaction, as predicted by intrapersonal spirituality, with contentment as a mediator } \\
\hline Total effect for spirituality & $1.06(.55)$ & $.91,1.21$ & 14.04 & $<.001$ \\
\hline Direct effect for spirituality & $.32(.17)$ & $.16, .49$ & 3.87 & $<.001$ \\
\hline Indirect effect through contentment & $.74(.38)$ & $.60, .88$ & & \\
\hline $\begin{array}{c}\text { Path } a_{1} \\
\text { (spirituality } \rightarrow \text { contentment) }\end{array}$ & $1.14(.62)$ & $.10,1.28$ & 15.80 & $<.001$ \\
\hline $\begin{array}{c}\text { Path } b_{1} \\
\text { (contentment } \rightarrow \text { life satisfaction) }\end{array}$ & $.65(.62)$ & $.56, .74$ & 14.02 & $<.001$ \\
\hline $\begin{array}{c}\text { Path } c^{\prime} \\
\text { (spirituality } \rightarrow \text { life satisfaction) }\end{array}$ & $.32(.17)$ & $.16, .49$ & 3.87 & $<.001$ \\
\hline \multicolumn{5}{|c|}{$R^{2}=.30$ for total effect. Sobel $z=10.48, p<.001$ for indirect effect. Ratio of indirect to total effect $=.70$} \\
\hline \multicolumn{5}{|c|}{ Life satisfaction, as predicted by overall social support, with overall positive emotions as a mediator } \\
\hline Total effect for social support & $.29(.53)$ & $.24, .33$ & 13.15 & $<.001$ \\
\hline Direct effect for social support & $.16(.21)$ & $.11, .20$ & 6.67 & $<.001$ \\
\hline Indirect effect through emotions & $.13(.32)$ & $.10, .16$ & & \\
\hline $\begin{array}{c}\text { Path } a_{1} \\
\text { (social support } \rightarrow \text { emotions) }\end{array}$ & $1.43(.59)$ & $1.22,1.63$ & 13.67 & $<.001$ \\
\hline $\begin{array}{c}\text { Path } b_{1} \\
\text { (emotions } \rightarrow \text { life satisfaction) }\end{array}$ & $.09(.55)$ & $.07, .11$ & 9.76 & $<.001$ \\
\hline $\begin{array}{c}\text { Path } \vec{c} \\
\text { (social support } \rightarrow \text { life satisfaction) }\end{array}$ & $.16(.21)$ & $.11, .20$ & 6.67 & $<.001$ \\
\hline \multicolumn{5}{|c|}{$R^{2}=.28$ for total effect. Sobel $z=7.93, p<.001$ for indirect effect. Ratio of indirect to total effect $=.45$} \\
\hline \multicolumn{5}{|c|}{ Life satisfaction, as predicted by overall social support, with contentment as a mediator } \\
\hline Total effect for social support & $.29(.53)$ & $.24, .33$ & 13.15 & $<.001$ \\
\hline Direct effect for social support & $.12(.23)$ & $.09, .16$ & 6.49 & $<.001$ \\
\hline Indirect effect through contentment & $.16(.30)$ & $.13, .20$ & & \\
\hline $\begin{array}{c}\text { Path } a_{1} \\
\text { (social support } \rightarrow \text { contentment) }\end{array}$ & $.25(.50)$ & $.21, .30$ & 11.90 & $<.001$ \\
\hline
\end{tabular}




\section{Continued}

\begin{tabular}{|c|c|c|c|c|}
\hline $\begin{array}{c}\text { Path } b_{1} \\
\text { (contentment } \rightarrow \text { life satisfaction) }\end{array}$ & $.64(.61)$ & $.56, .71$ & 17.11 & $<.001$ \\
\hline $\begin{array}{c}\text { Path } \mathcal{c} \\
\text { (social support } \rightarrow \text { life satisfaction) }\end{array}$ & $.12(.23)$ & $.09, .16$ & 6.49 & $<.001$ \\
\hline \multicolumn{5}{|c|}{$R^{2}=.28$ for total effect. Sobel $z=7.76, p<.001$ for indirect effect. Ratio of indirect to total effect $=.56$} \\
\hline \multicolumn{5}{|c|}{ Life satisfaction, as predicted by resilience, with overall positive emotions as a mediator } \\
\hline Total effect for resilience & $.46(.49)$ & $.37, .55$ & 1.24 & $<.001$ \\
\hline Direct effect for resilience & $.19(.13)$ & $.09, .29$ & 3.74 & $<.001$ \\
\hline Indirect effect through emotions & $.27(.36)$ & $.21, .34$ & & \\
\hline $\begin{array}{c}\text { Path } a_{1} \\
\text { (resilience } \rightarrow \text { emotions) }\end{array}$ & $2.74(.60)$ & $2.37,3.10$ & 14.69 & $<.001$ \\
\hline $\begin{array}{c}\text { Path } b_{1} \\
\text { (emotions } \rightarrow \text { life satisfaction) }\end{array}$ & $.10(.60)$ & $.08, .12$ & 9.81 & $<.001$ \\
\hline $\begin{array}{c}\text { Path } c^{2} \\
\text { (resilience } \rightarrow \text { life satisfaction) }\end{array}$ & $.19(.13)$ & $.09, .29$ & 3.74 & $<.001$ \\
\hline \multicolumn{5}{|c|}{$R^{2}=.24$ for total effect. Sobel $z=8.15, p<.001$ for indirect effect. Ratio of indirect to total effect $=.59$} \\
\hline \multicolumn{5}{|c|}{ Life satisfaction, as predicted by resilience, with contentment as a mediator } \\
\hline Total effect for resilience & $.46(.49)$ & $.37, .55$ & 1.24 & $<.001$ \\
\hline Direct effect for resilience & $.10(.10)$ & $.01, .19$ & 3.74 & $<.001$ \\
\hline Indirect effect through contentment & $.37(.39)$ & $.30, .44$ & & \\
\hline $\begin{array}{c}\text { Path } a_{1} \\
\text { (resilience } \rightarrow \text { contentment) }\end{array}$ & $.53(.58)$ & $.46, .60$ & 14.52 & $<.001$ \\
\hline $\begin{array}{c}\text { Path } b_{1} \\
\text { (contentment } \rightarrow \text { life satisfaction) }\end{array}$ & $.70(.66)$ & $.61, .79$ & 15.04 & $<.001$ \\
\hline $\begin{array}{c}\text { Path } \vec{c} \\
\text { (resilience } \rightarrow \text { life satisfaction) }\end{array}$ & $.10(.10)$ & $.01, .19$ & 2.08 & .038 \\
\hline \multicolumn{5}{|c|}{$R^{2}=.24$ for total effect. Sobel $z=10.43, p<.001$ for indirect effect. Ratio of indirect to total effect $=.79$} \\
\hline \multicolumn{5}{|c|}{ Life satisfaction, as predicted by intrapersonal spirituality, and mediated through pride, resilience, and contentment } \\
\hline Total effect for spirituality & $1.06(.55)$ & $.91,1.21$ & 14.04 & $<.001$ \\
\hline Direct effect for spirituality & $.28(.14)$ & $.10, .46$ & 3.07 & .002 \\
\hline Total indirect effects & $.78(.41)$ & $.63, .94$ & & \\
\hline Indirect effect through pride & $.03(.02)$ & $-.10, .17$ & & \\
\hline $\begin{array}{l}\text { Indirect effect through pride } \\
\text { and resilience }\end{array}$ & $.03(.01)$ & $-.02, .08$ & & \\
\hline $\begin{array}{l}\text { Indirect effect through pride } \\
\text { and contentment }\end{array}$ & $.35(.18)$ & $.25, .45$ & & \\
\hline $\begin{array}{l}\text { Indirect effect through pride, } \\
\text { resilience, and contentment }\end{array}$ & $.05(.02)$ & $.02, .08$ & & \\
\hline Indirect effect through resilience & $.03(.01)$ & $-.02, .09$ & & \\
\hline $\begin{array}{l}\text { Indirect effect through resilience } \\
\text { and contentment }\end{array}$ & $.05(.03)$ & $.02, .09$ & & \\
\hline
\end{tabular}




\section{Continued}

Indirect effect through contentment

Path $a_{1}$

(spirituality $\rightarrow$ pride)

Path $d_{21}$

(pride $\rightarrow$ resilience)

Path $a_{2}$

(spirituality $\rightarrow$ resilience)

Path $d_{31}$

(pride $\rightarrow$ contentment)

Path $d_{32}$

(resilience $\rightarrow$ contentment)

Path $a_{3}$

(spirituality $\rightarrow$ contentment)

Path $b_{1}$

(pride $\rightarrow$ life satisfaction)

Path $b_{2}$

(resilience $\rightarrow$ life satisfaction)

Path $b_{3}$

(contentment $\rightarrow$ life satisfaction)

Path $\mathcal{c}^{\prime}$

(spirituality $\rightarrow$ life satisfaction)
$.26(.13)$

$.15, .38$

$.95(.62)$

$.84,1.08$

$.42, .68$

$.38, .78$

$.47, .70$

$.07, .22$

$.25, .59$

$-0.10,0.17$

$-0.05,0.15$

$0.50,0.72$

$0.10,0.46$

$0.28(.14)$

$.14(.16)$

$0.05(.05)$

$0.61(.58)$

15.33

$<.001$

8.24

$<.001$

5.69

$<.001$

$<.001$

0.68

$<.001$

Ratio of indirect to total effect for total indirect effects $=.74$. Ratio of indirect to total effect for indirect effect through pride $=.02$; through pride and resilience $=.02$; through pride and contentment $=.32$;

through pride, resilience, and contentment $=.04$; through resilience $=.03$; through resilience and contentment $=.05$;

and through contentment $=.24$.

Note. PROCESS establishes significance by confidence intervals that do not contain a zero. Where available, $t$ - and $p$-values have been included as well. Results from the Sobel normal theory test for mediation are also provided for simple mediation analyses. Standardized coefficients are provided in parentheses. $N=428$.

relationships among the variables are diagrammed in Figure 1. Indirect effects accounted for nearly three quarters of the total effect for intrapersonal spirituality's prediction of life satisfaction. The path from intrapersonal spirituality through pride and contentment to life satisfaction was strongest, accounting for approximately one third of the total effect, followed closely by the path through contentment alone. Neither pride nor resilience directly predicted life satisfaction, but were both linked to it through contentment. The model's effect size was large.

\section{Discussion}

The distinction between preventing illness and promoting health has gained considerable attention over the past few decades and the importance of promoting psychological well-being is now widely recognized. The present study confirms the importance of spirituality, social support, and positive emotions as potential sources of well-being. Findings also support the need for continuing to 


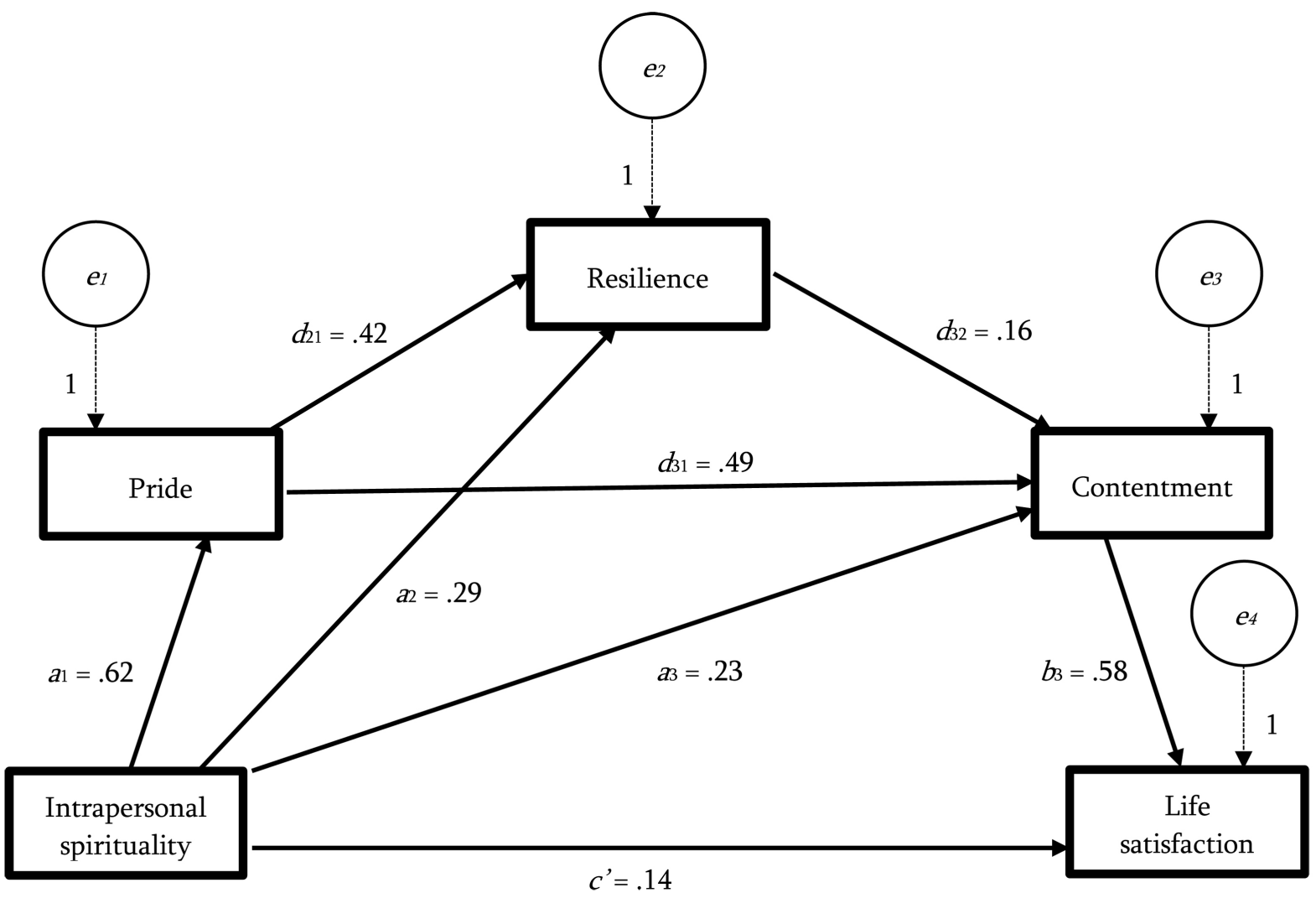

Figure 1. Significant pathways from intrapersonal spirituality to life satisfaction, as mediated through pride, resilience, and contentment (all $p s<.001$ ). Direct paths from pride and resilience to life satisfaction were not significant. Coefficients are standardized. Unstandardized coefficients and $p$-values are presented in Table 7.

distinguish among types of well-being, as they may differentially relate to various predictive factors. Some factors may benefit well-being in general, while others may be specific to either strength or comfort; resilience requires unusual strength and may be generated by factors specific to confidence and tenacity, whereas life satisfaction may be promoted more by factors related to contentment. The study also demonstrated the differential benefits of various aspects of spirituality and of types of positive emotions.

Spirituality is widely recognized as a potential source of both strength and comfort (Fombuena et al., 2016) and it strongly predicted both resilience and life satisfaction in the present study. The benefits of spirituality have typically been ascribed either to connection with others (Seybold \& Hill, 2001; Miller \& Kelley, 2005) or to an experience of transcendence and awe (Van Cappellen et al., 2016). In contrast, the present study found only the intrapersonal dimension of spirituality to predict resilience and life satisfaction; neither interpersonal nor transpersonal spirituality predicted well-being for this sample of young adults. Emerging adulthood may have unique characteristics in terms of new-found cognitive abilities and desires for forging an identity. Intrapersonal spirituality involves experiencing one's life as meaningful and purposeful. Transpersonal spirituality may be especially well-suited to later developmental stages, with their 
corresponding interest in even deeper questions regarding the meaning of life and a search for connection that transcends humankind (Erikson, 1959). Indeed, many studies that have found transpersonal spirituality to be helpful have involved adults who are not college students and are in their 30s or older (e.g., Van Cappellen et al., 2016). The benefits of experiencing awe are well-documented (Piff, Dietze, Feinberg, Stancato, \& Keltner, 2015), but it is important not to overlook the potential significance of other dimensions as well. Further research is needed to consider the potential interplay between developmental issues and dimensions of spirituality.

Social support directly predicted life satisfaction and more strongly than it predicted resilience. Its effect on resilience was mediated through positive emotions. As noted earlier, other studies have found social support to predict resilience as well as life satisfaction, but they do not all involve young adults. Findings for a positive relationship between social support and resilience in emerging adulthood have not been consistent (Gerson et al., 2015) and the impact of social support has been found in other studies to depend on the meaning it has for the recipient (Janssen et al., 2011; Varni et al., 1992). Early adulthood is a time for establishing one's identity and "forging out" on one's own. Looking to others for support out of need may not reflect strength at this time in one's life. In contrast, social support may be important for safety and security in both childhood and late in adulthood. Further research is needed regarding the changing implications each factor may have through the lifespan.

Consistent with the broaden-and-build theory, positive emotions played important roles in facilitating both resilience and life satisfaction. Findings suggested that at least some of the effect for both intrapersonal spirituality and social support was mediated through positive emotions. Positive emotions may lead directly to strength and satisfaction as well as open a person up to new experiences that build well-being (Fredrickson, 2004). It is likely that positive emotions both promote and result from well-being, generating a beneficial cycle. Further research is needed to assess causal directions and possible bi-directionality.

Individual positive emotions have been linked to specific tendencies, such as pride to "dreaming big", contentment to savoring, and amusement to laughing (Fredrickson, 2013). Accordingly, the positive emotions found to be most beneficial for resilience and life satisfaction differed. As hypothesized, pride strongly predicted resilience. This finding is consistent with previous research linking pride to resilience in older adults (Janssen et al., 2011), to perseverance (Williams \& DeSteno, 2008), and to achievement motivation (Tracy \& Robins, 2007b), as well as with findings for a resilient explanatory style (Gerson \& Fernandez, 2013). Contentment also predicted resilience, although not as strongly as pride. One could surmise that contentment could confer a needed sense of stability for strength, but such speculation would require further research. While not the focus of this study, amusement also predicted resilience. This finding is 
consistent with other studies, which have found humor to have many benefits, including psychological well-being (Kazarian \& Martin, 2004; Maiolino \& Kuiper, 2016) and resilience (Kuiper, 2012). Contentment was the sole emotion to significantly predict life satisfaction. The value of contentment and serenity is consistent with findings for the benefits of meditation (Fredrickson, Cohn, Coffey, Pek, \& Finkel, 2008; Khoury et al., 2013). That contentment was more important than joy also supports the assertion that resilience and life satisfaction are not synonymous with feeling "happy".

Positive emotions were differentially related to intrapersonal spirituality and social support as well. Intrapersonal spirituality was predicted by all emotions except for love, and pride was its strongest predictor. Pride is not usually thought of as connected to spirituality or religion in a positive way (Tracy \& Robins, 2007a), but it may lead one to "dream big" (Fredrickson, 2013: p. 5) and to feel confident and self-assured. It may also be more self-focused than other-connected, which may be the case as well for intrapersonal spirituality and helpful for building strength in emerging adulthood. In contrast, only love, contentment, and joy predicted perceived social support. Love is by its nature other-connected, leading to mutual care and feelings of closeness and trust.

Both pride and resilience were linked to life satisfaction, as mediated through contentment. The ability to overcome obstacles may lead to such positive emotions as contentment, which in turn produce comfort and satisfaction. Hence, resilience may provide a foundation for future life satisfaction, but does not guarantee it. One may be proud and strong, but not necessarily satisfied.

\section{Limitations and Recommendations}

This study was largely exploratory and has a number of limitations. The most problematic element is the study's design. This was a correlational study, which can establish, at best, covariation between variables. As noted by Hayes (2013), "Causality is the cinnamon bun of social science. It is a sticky concept, and establishing that a sequence of events is a causal one can be a messy undertaking" (p. 17). As with all correlational designs, there is no way of being sure about the causal ordering of the relationships. Even path analyses cannot establish causality, which is an issue of research design rather than one of statistics. Establishing pathways in the present study is particularly "sticky", given that factors such as spirituality, social support, resilience, and life satisfaction are likely to be connected to positive emotions bi-directionally, with each building on the other. The path models described are ones that make sense in light of theory, but they are only among several possible explanations for the findings.

Furthermore, the present study considered positive emotions as possible mediators between variables. It is likely that many more mediators are involved, as well as mediators between mediators. This study provides one potentially helpful snapshot of several processes. It is only through many snapshots and many measures that one can start to untangle some of the linkages among variables 
(Hayes, 2013).

The study used only self-report measures, at one point in time. Self-report is limited by such factors as possible lack of awareness, defensiveness, or boredom. It is especially useful, however, for assessing participants' own perceptions of a meaningful life, of their support by others, of their life as meeting personal goals, or of their current emotional states. Behavioral or observational measures are also helpful, however, and have been widely used for assessing both resilience and social support. Follow-up studies could explore additional ways of assessing each of the factors. Tracy et al.'s (2012) research on nonverbal expressions, for example, has demonstrated that pride has recognizable facial or bodily manifestations. Multiple assessments over time may be helpful in teasing out some of the causal links as well.

Participants also completed all measures independently and online. It was not possible to ensure that they took the process seriously or completed the surveys in a quiet setting. Environments are likely to have varied. Some participants may have completed the surveys in one sitting, while others may have taken breaks. Follow-up studies should control for as many of these variables as possible.

Finally, the sample was limited to university students from a small, private, religiously-affiliated institution in southern California and a large public university in Utah. The sample is likely to have consisted of a large number of Christian or Mormon participants. Furthermore, most participants were Caucasian women in their early 20s. More research is needed on resilience and life satisfaction in emerging adulthood, with people in a variety of life circumstances and with diverse backgrounds. The relative importance of spirituality or social support may differ according to such factors as gender, culture, religion, economic need, or geographical region.

\section{Future Directions}

Studies using experimental designs are needed to clarify the directional relationships, while also being careful not to close off the possibilities of complex loops or sequences among variables. It is likely that with health-related issues, one variable, such as social connection, may lead to another, such as contentment, which may then build further social connection as well as additional factors, such as life satisfaction and/or intrapersonal spirituality, and so forth. Attempting experimentally to establish a single direction between two variables may be misleading. Experiments must consider the possibility of a complex interplay among the variables.

The benefits assumed to be derived from such factors as spirituality or social support may be largely conferred by the positive emotions the factors generate. Such emotions as contentment, pride, amusement, and awe can undoubtedly be produced in a variety of ways. Research has demonstrated the benefits of meditating, expressing gratitude, counting blessings, experiencing awe-inspiring environments, connecting with others, and so forth. Developing as many avenues 
as possible to inspire various emotions may be helpful for applications in real-world settings.

Furthermore, specific positive emotions may be most relevant for particular aspects of well-being. Future research could explore which positive emotions may be key to promoting specific types of well-being. Fredrickson's (2013) research has focused on 10 emotions and the present study considered seven. Many of these emotions coincide (i.e., pride, amusement, contentment, joy, love, and awe) but some do not (i.e., compassion in the present study and interest, hope, inspiration, and gratitude in Fredrickson's research), and the lists are by no means exhaustive (Fredrickson, 2013). Research should also explore which additional emotions may be important.

Finally, the field should continue to consider the potential role of individual differences in determining the most effective routes to particular emotions. Developmental stage is often overlooked as an important factor. What leads to contentment in a young child, adolescent, or adult is likely to differ, as it may for adults attending to the tasks inherent in emerging, middle, and late adulthood. It is important to identify viable sources of the various emotions, resilience, life satisfaction, and other aspects of well-being, as they may relate to different developmental stages.

\section{Conclusion}

Distinct aspects of spirituality, perceived social support, and specific positive emotions were found differentially to predict resilience and life satisfaction. The search for purpose and meaning inherent in intrapersonal spirituality predicted both resilience and life satisfaction; other aspects of spirituality did not predict either type of well-being in this sample of emerging adults. Furthermore, perceived social support directly predicted only life satisfaction. Although positive emotions, overall, were strong predictors of both resilience and life satisfaction, the key emotions differed for each factor. Pride was directly associated with both intrapersonal spirituality and resilience, but not with life satisfaction. Contentment, on the other hand, was directly associated with both resilience and life satisfaction and mediated the relationship between these two aspects of well-being.

The relative importance of positive emotions for well-being has a number of interesting implications. This finding may help explain some of the inconsistencies regarding the impact of such factors as spirituality and social support, as the meaning and emotional effect of each factor for an individual may be at least as important as characteristics inherent in the factor itself. It also expands the possible pathways to well-being, beyond spirituality and social support. For example, many experiences besides spirituality, such as success in work or acknowledgement by others, may help instill pride in a person. Likewise, factors other than social support, such as meditating or being surrounded by beauty, may lead to contentment. Identifying multiple possible avenues to the various positive emotions may be a fruitful focus for future studies. 
Finally, the effects of various factors may depend on the developmental tasks at hand. A personal search for meaning and purpose may be especially important for building resilience in emerging adulthood-a stage during which the individual is establishing an identity as an independent adult. While perceived social support may not promote strength during this period, it predicts contentment and life satisfaction. Considering the needs of the individual at different points of development may be important for identifying the factors that will promote various types of well-being.

\section{References}

American Psychological Association (2002). Ethical Principles of Psychologists and Code of Conduct. American Psychologist, 57, 1060-1073. https://doi.org/10.1037/0003-066X.57.12.1060

Anum, J., \& Dasti, R. (2016). Caregiver Burden, Spirituality, and Psychological Well-Being of Parents Having Children with Thalassemia. Journal of Religion and Health, 55, 941-955. https://doi.org/10.1007/s10943-015-0127-1

Archana, Kumar, U., \& Singh, R. (2014). Resilience and Spirituality as Predictors of Psychological Well-Being among University Students. Journal of Psychosocial Research, 9, 227-235.

Bonanno, G. A. (2004). Loss, Trauma, and Human Resilience. American Psychologist, 59, 20-28. https://doi.org/10.1037/0003-066X.59.1.20

Burris, J. L., Brechting, E. H., Salsman, J., \& Carlson, C. R. (2009). Factors Associated With the Psychological Well-Being and Distress of University Students. Journal of American College Health, 57, 536-543. https://doi.org/10.3200/JACH.57.5.536-544

Büssing, A., Baumann, K., Hvidt, N. C., Koenig, H. G., Puchalski, C. M., \& Swinton, J. (2014). Editorial: Spirituality and Health. Evidence-Based Complementary and Alternative Medicine, 2014, Article ID: 682817. https://doi.org/10.1155/2014/682817

Carver, C. S., Sinclair, S., \& Johnson, S. L. (2010). Authentic and Hubristic Pride: Differential Relations to Aspects of Goal Regulation, Affect, and Self-Control. Journal of Research in Personality, 44, 698-703. https://doi.org/10.1016/j.jrp.2010.09.004

Cassell, E. J. (1976). Illness and Disease. The Hastings Center Report, 6, 27-37. https://doi.org/10.2307/3561497

Cobb, S. (1976). Social Support as a Moderator of Stress. Psychosomatic Medicine, 38, 300-314. https://doi.org/10.1097/00006842-197609000-00003

Cohen, J. (1992). A Power Primer. Psychological Bulletin, 112, 155-159. https://doi.org/10.1037/0033-2909.112.1.155

Cohn, M. A., Fredrickson, B. L., Brown, S. L., Mikels, J. A., \& Conway, A. M. (2009). Happiness Unpacked: Positive Emotions Increase Life Satisfaction by Building Resilience. Emotion, 9, 361-368. https://doi.org/10.1037/a0015952

Connor, K. M., \& Davidson, J. R. (2003). Development of a New Resilience Scale: The Connor-Davidson Resilience Scale. Depression and Anxiety, 18, 76-82. https://doi.org/10.1002/da.10113

Delaney, C. (2005). The Spirituality Scale: Development and Psychometric Testing of a Holistic Instrument to Assess the Human Spiritual Dimension. Journal of Holistic Nursing, 23, 145-166. https://doi.org/10.1177/0898010105276180

Diener, E., Emmons, R. A., Larsen, R. J., \& Griffin, S. (1985). The Satisfaction with Life Scale. Journal of Personality Assessment, 49, 71-75. 
https://doi.org/10.1207/s15327752jpa4901_13

Donnellan, W. J., Bennett, K. M., \& Soulsby, L. K. (2017). Family Close but Friends Closer: Exploring Social Support and Resilience in Older Spousal Dementia Careers. Aging and Mental Health, 21, 1222-1228. https://doi.org/10.1080/13607863.2016.1209734

Erikson, E. H. (1959). Identity and the Life Cycle. New York, NY: W.W. Norton.

Faul, F., Erdfelder, E., Lang, A., \& Buchner, A. (2007). GPower 3: A Flexible Statistical Power Analysis Program for the Social, Behavioral, and Biomedical Sciences. Behavior Research Methods, 39, 175-191. https://doi.org/10.3758/BF03193146

Fombuena, M., Galiana, L., Barreto, P., Oliver, A., Pascual, A., \& Soto-Rubio, A. (2016). Spirituality in Patients with Advanced Illness: The Role of Symptom Control, Resilience and Social Network. Journal of Health Psychology, 21, 2765-2774. https://doi.org/10.1177/1359105315586213

Foskett, J., Marriott, J., \& Wilson, R. F. (2004). Mental Health, Religion and Spirituality: Attitudes, Experience and Expertise among Mental Health Professionals and Religious Leaders in Somerset. Mental Health, Religion and Culture, 7, 5-22.

https://doi.org/10.1080/13674670310001602490

Fredrickson, B. L. (1998). What Good Are Positive Emotions? Review of General Psychology, 2, 300-319. https://doi.org/10.1037/1089-2680.2.3.300

Fredrickson, B. L. (2001). The Role of Positive Emotions in Positive Psychology: The Broaden-and-Build Theory of Positive Emotions. American Psychologist, 56, 218-226. https://doi.org/10.1037/0003-066X.56.3.218

Fredrickson, B. L. (2004). The Broaden-and-Build Theory of Positive Emotions. Philosophical Transactions of the Royal Society B, 359, 1367-1377.

https://doi.org/10.1098/rstb.2004.1512

Fredrickson, B. L. (2013). Positive Emotions Broaden and Build. In P. Devine, \& A. Plant (Eds.), Advances in Experimental Social Psychology (pp. 1-53). Vol. 47, Burlington: Academic Press. https://doi.org/10.1016/B978-0-12-407236-7.00001-2

Fredrickson, B. L., Cohn, M. A., Coffey, K. A., Pek, J., \& Finkel, S. M. (2008). Open Hearts Build Lives: Positive Emotions, Induced Through Loving-Kindness Meditation, Build Consequential Personal Resources. Journal of Personality and Social Psychology, 95, 1045-1062. https://doi.org/10.1037/a0013262

Gerson, M. W., \& Fernandez, N. (2013). PATH: A Program to Build Resilience and Thriving in Undergraduates. Journal of Applied Social Psychology, 43, 2169-2184. https://doi.org/10.1111/jasp.12168

Gerson, M. W., Fahmy, P., Glossbrenner, E., \& Mullen, S. (2015). Predictors of Resilience and Thriving: Spirituality and Social Support. Poster Presented at the Annual Western Psychological Association Convention in Las Vegas.

Hayes, A. F. (2013). Introduction to Mediation, Moderation, and Conditional Process Analysis. New York, NY: The Guilford Press.

Hill, P. L, Payne, B. R., Jackson, J. J., Stine-Morrow, E. A. L., \& Roberts, B. W. (2014). Social Support Predicts Increased Conscientiousness during Older Adulthood. Journals of Gerontology, Series B: Psychological Sciences and Social Sciences, 69, 543-547. https://doi.org/10.1093/geronb/gbt024

Infuma, F. J., \& Luthar, S. S. (2017). The Multidimensional Nature of Resilience to Spousal Loss. Journal of Personality and Social Psychology, 112, 926-947. https://doi.org/10.1037/pspp0000095

Janssen, B. M., Regenmortel, T. V., \& Abma, T. A. (2011). Identifying Sources of Strength: Resilience from the Perspective of Older People Receiving Long-Term 
Community Care. European Journal of Ageing, 8, 145-156. https://doi.org/10.1007/s10433-011-0190-8

Jiménez Ambriz, M., Izal, M., \& Montorio, I. (2012). Psychological and Social Factors That Promote Positive Adaptation to Stress and Adversity in the Adult Life Cycle. Journal of Happiness Studies, 13, 833-848. https://doi.org/10.1007/s10902-011-9294-2

Kazarian, S. S., \& Martin, R. A. (2004). Humour Styles, Personality, and Well-Being among Lebanese University Students. European Journal of Personality, 18, 209-219. https://doi.org/10.1002/per.505

Khoury, B., Lecomte, T., Fortin, G., Masse, M., Therien, P., Bouchard, V., Chapleau, M. A., Paquin, K., \& Hofmann, S. G. (2013). Mindfulness-Based Therapy: A Comprehensive Meta-Analysis. Clinical Psychology Review, 33, 763-771. https://doi.org/10.1016/j.cpr.2013.05.005

Koenig, H. G. (2007). Spirituality and Depression: A Look at the Evidence. Southern Medical Journal, 100, 737-739. https://doi.org/10.1097/SMJ.0b013e318073c68c

Koenig, H. G. (2012). Religion, Spirituality, and Health: The Research and Clinical Implications. ISRN Psychiatry, 2012, Article ID: 278730. https://doi.org/10.5402/2012/278730

Kuiper, N. A. (2012). Humor and Resiliency: Towards a Process Model of Coping and Growth. Europe's Journal of Psychology, 8, 475-491. https://doi.org/10.5964/ejop.v8i3.464

Luthar, S. S., Cicchetti, D., \& Becker, B. (2000). The Construct of Resilience: A Critical Evaluation and Guidelines for Future Work. Child Development, 71, 543-562. https://doi.org/10.1111/1467-8624.00164

Maiolino, N., \& Kuiper, N. (2016). Examining the Impact of a Brief Humor Exercise on Psychological Well-Being. Translational Issues in Psychological Science, 2, 4-13. https://doi.org/10.1037/tps0000065

Masten, A. S. (1999). Resilience Comes of Age: Reflections on the Past and Outlook for the Next Generation of Research. In M. D. Glantz, J. Johnson, \& L. Huffman (Eds.), Resilience and Development: Positive Life Adaptations (pp. 282-296). New York: Plenum.

Masten, A. S., \& Reed, M.-G. J. (2002). Resilience in Development. In C. R. Snyder, \& S. J. Lopez (Eds.), Handbook of Positive Psychology (pp. 74-88). New York: Oxford University Press.

Miller, L., \& Kelley, B. S. (2005). Relationships of Religiosity and Spirituality with Mental Health and Psychopathology. In R. F. Paloutzian, \& C. L. Park (Eds.), Handbook of the Psychology of Religion and Spirituality (pp. 460-478). New York, NY: Guilford Press.

Oman, D., \& Thoresen, C. E. (2005). Do Religion and Spirituality Influence Health? In R. F. Paloutzian, \& C. L. Park (Eds.), Handbook of the Psychology of Religion and Spirituality (pp. 435-459). New York, NY: Guilford Press.

Pavot, W., \& Diener, E. (2008). The Satisfaction With Life Scale and the Emerging Construct of Life Satisfaction. The Journal of Positive Psychology, 3, 137-152. https://doi.org/10.1080/17439760701756946

Perrier, C. P. K., Boucher, R., Etchegary, H., Sadava, S. W., \& Molnar, D. S. (2010). The Overlapping Contributions of Attachment Orientation and Social Support in Predicting Life-Events Distress. Canadian Journal of Behavioural Science, 42, 71-79. https://doi.org/10.1037/a0018337

Piedmont, R. L. (1999). Does Spirituality Represent the Sixth Factor of Personality? Spiritual Transcendence and the Five-Factor Model. Journal of Personality, 67, 985-1013. https://doi.org/10.1111/1467-6494.00080 
Piff, P., Dietze, P., Feinberg, M., Stancato, D. M., \& Keltner, D. (2015). Awe, the Small Self, and Prosocial Behavior. Journal of Personality and Social Psychology, 108, 883-899. https://doi.org/10.1037/pspi0000018

Porter, K. E., Brennan-Ing, M., Burr, J. A., Dugan, E., \& Karpiak, S. E. (2017). Stigma and Psychological Well-Being among Older Adults with HIV: The Impact of Spirituality and Integrative Health Approaches. The Gerontologist, 57, 219-228.

Reivich, K., Gillham, J. E., Chaplin, T. M., \& Seligman, M. E. (2013). From Helplessness to Optimism: The Role of Resilience in Treating and Preventing Depression in Youth. In S. Goldstein, \& R. B. Brooks (Eds.), Handbook of Resilience in Children, (2nd ed., pp. 201-214). New York, NY: Springer Science and Business Media. https://doi.org/10.1007/978-1-4614-3661-4_12

Ryff, C. D., \& Keyes, C. L. M. (1995). The Structure of Psychological Well-Being Revisited. Journal of Personality and Social Psychology, 69, 719-727.

https://doi.org/10.1037/0022-3514.69.4.719

Ryff, C. D., \& Singer, B. H. (2008). Know Thyself and Become What You Are: A Eudaimonic Approach to Psychological Well-Being. Journal of Happiness Studies, 9, 13-39. https://doi.org/10.1007/s10902-006-9019-0

Saroglou, V. (2014). Introduction: Studying Religion in Personality and Social Psychology. In V. Saroglou (Ed.), Religion, Personality, and Social Behavior (pp. 1-28). New York, NY: Psychology Press.

Secor, S. P., Limke-McLean, A., \& Wright, R. W. (2017). Whose Support Matters? Support of Friends (Not Family) May Predict Affect and Well-Being of Adults Faced With Negative Life Events. Journal of Relationships Research, 8, 1-10.

https://doi.org/10.1017/jrr.2017.10

Selby, D., Seccaraccia, D., Huth, J., Kurrpa, K., \& Fitch, M. (2016). A Qualitative Analysis of a Healthcare Professional's Understanding and Approach to Management of Spiritual Distress in an Acute Care Setting. Journal of Palliative Medicine, 19, 1197-1204. https://doi.org/10.1089/jpm.2016.0135

Seybold, K. S., \& Hill, P. C. (2001). The Role of Religion and Spirituality in Mental and Physical Health. Current Directions in Psychological Science, 10, 21-24. https://doi.org/10.1111/1467-8721.00106

Shiota, M. N., Keltner, D., \& John, O. P. (2006). Positive Emotion Dispositions Differentially Associated With Big Five Personality and Attachment Style. Journal of Positive Psychology, 1, 61-71. https://doi.org/10.1080/17439760500510833

Smith, B. W., Tooley, E. M., Christopher, P. J., \& Kay V. S. (2010). Resilience as the Ability to Bounce Back from Stress: A Neglected Personal Resource? The Journal of Positive Psychology, 5, 166-176. https://doi.org/10.1080/17439760.2010.482186

Smith, C., \& Carlson, B. E. (1997). Stress, Coping, and Resilience in Children and Youth. Social Service Review, 71, 231-256. https://doi.org/10.1086/604249

Tracy, J. L., \& Robins, R. W. (2004). Putting the Self into Self-Conscious Emotions: A Theoretical Model. Psychological Inquiry, 15, 103-125.

https://doi.org/10.1207/s15327965pli1502_01

Tracy, J. L., \& Robins, R. W. (2007a). Emerging Insights into the Nature and Function of Pride. Current Directions in Psychological Science, 16, 147-150. https://doi.org/10.1111/j.1467-8721.2007.00493.x

Tracy, J. L., \& Robins, R. W. (2007b). The Nature of Pride. In J. L. Tracy, R. W. Robins, \& J. P. Tangney (Eds.), The Self-Conscious Emotions: Theory and Research (pp. 263-282). New York, NY: The Guilford Press. 
Tracy, J. L., \& Robins, R. W. (2007c). The Psychological Structure of Pride: A Tale of Two Facets. Journal of Personality and Social Psychology, 92, 506-525. https://doi.org/10.1037/0022-3514.92.3.506

Tracy, J. L., \& Robins, R. W. (2007d). The Self in Self-Conscious Emotions: A Cognitive Appraisal Approach. In J. L. Tracy, R. W. Robins, \& J. P. Tangney (Eds.), The Self-Conscious Emotions: Theory and Research (pp. 3-20). New York, NY: The Guilford Press.

Tracy, J. L., \& Robins, R. W. (2014). Commentary: Conceptual and Empirical Strengths of the Authentic/Hubristic Model of Pride. Emotion, 14, 33-37. https://doi.org/10.1037/a0034490

Tracy, J. L., Cheng, J. T., Robins, R. W., \& Trzesniewski, K. H. (2009). Authentic and Hubristic Pride: The Affective Core of Self-Esteem and Narcissism. Self and Identity, 8 , 196-213. https://doi.org/10.1080/15298860802505053

Tracy, J. L., Shariff, A. F., Zhao, W., \& Henrich, J. (2012). Cross-Cultural Evidence That the Nonverbal Expression of Pride is an Automatic Status Signal. Journal of Experimental Psychology: General, 142, 163-180. https://doi.org/10.1037/a0028412

Van Cappellen, P., Toth-Gauthier, M., Saroglou, V., \& Fredrickson, B. L. (2016). Religion and Well-Being: The Mediating Role of Positive Emotions. Journal of Happiness Studies, 17, 485-505. https://doi.org/10.1007/s10902-014-9605-5

Varni, J., Setoguchi, Y., Rappaport, L., \& Talbot, D. (1992). Psychological Adjustment and Social Support with Congenital/Acquired Limb Deficiencies. Journal of Behavioral Medicine, 15, 31-44. https://doi.org/10.1007/BF00848376

Williams, L. A., \& DeSteno, D. (2008). Pride and Perseverance. The Motivational Function of Pride. Journal of Personality and Social Psychology, 94, 1007.

https://doi.org/10.1037/0022-3514.94.6.1007

Windle, G. (2011). What is Resilience? A Review and Concept Analysis. Reviews in Clinical Gerontology, 21, 152-169. https://doi.org/10.1017/S0959259810000420

Yurgelun-Todd, D. (2007). Emotional and Cognitive Changes during Adolescence. Current Opinion in Neurobiology, 17, 251-257. https://doi.org/10.1016/j.conb.2007.03.009

Zimet, G. D., Dahlem, N. W., Zimet, S. G., \& Farley, G. K. (1988). The Multidimensional Scale of Social Support. Journal of Personality Assessment, 52, 30-41. https://doi.org/10.1207/s15327752jpa5201_2

Zimet, G. D., Powell, S. S., Farley, G. K., Werkman, S., \& Berkoff, K. A. (1990). Psychometric Characteristics of the Multidimensional Scale of Social support. Journal of Personality Assessment, 55, 610-617. https://doi.org/10.1080/00223891.1990.9674095 